Article

\title{
High Cysteinyl Leukotriene Receptor 1 Expression Correlates with Poor Survival of Uveal Melanoma Patients and Cognate Antagonist Drugs Modulate the Growth, Cancer Secretome, and Metabolism of Uveal Melanoma Cells
}

\author{
Kayleigh Slater ${ }^{1,2}{ }^{\circledR}$, Aisling B. Heeran ${ }^{3}$, Sandra Garcia-Mulero ${ }^{4,5}{ }^{\oplus}$, Helen Kalirai ${ }^{6}$, \\ Rebeca Sanz-Pamplona 4(D), Arman Rahman ${ }^{1}$, Nebras Al-Attar 1(D, Mays Helmi ${ }^{7}$, \\ Fiona $\mathrm{O}^{\prime}$ Connell $^{3}{ }^{\mathbb{D}}$, Rosa Bosch ${ }^{8}$, Anna Portela ${ }^{8}$, Alberto Villanueva ${ }^{8}$, \\ William M. Gallagher ${ }^{1}\left(\mathbb{D}\right.$, Lasse D. Jensen ${ }^{7}\left(\mathbb{D}\right.$, Josep M. Piulats ${ }^{9,10}$, Sarah E. Coupland ${ }^{6,11} \mathbb{D}^{(}$, \\ Jacintha $\mathrm{O}^{\prime}$ Sullivan ${ }^{3}$ and Breandán N. Kennedy ${ }^{1, *(D)}$ \\ 1 UCD School of Biomolecular and Biomedical Science, UCD Conway Institute, University College Dublin, \\ D04 V1W8 Dublin, Ireland; kayleigh.slater@ucdconnect.ie (K.S.); arman.rahman@ucd.ie (A.R.); \\ nebras.alattar@ucd.ie (N.A.-A.); William.Gallagher@ucd.ie (W.M.G.) \\ 2 Genomics Medicine Ireland Limited, Cherrywood Business Park Building 4, D18 K7W4 Dublin, Ireland \\ 3 Trinity Translational Medicine Institute, Department of Surgery, Trinity College Dublin, St. James's Hospital, \\ D08 W9RT Dublin, Ireland; HEERANA@tcd.ie (A.B.H.); oconnefi@tcd.ie (F.O.); osullij4@tcd.ie (J.O.) \\ 4 Unit of Biomarkers and Susceptibility, Oncology Data Analytics Program (ODAP), Catalan Institute of \\ Oncology (ICO), Oncobell Program, Bellvitge Biomedical Research Institute (IDIBELL) and CIBERESP, \\ L'Hospitalet de Llobregat, 08908 Barcelona, Spain; s.garciam@idibell.cat (S.G.-M.); \\ rebecasanz@iconcologia.net (R.S.-P.) \\ 5 Department of Clinical Sciences, Faculty of Medicine and Health Sciences, University of Barcelona, \\ 08036 Barcelona, Spain \\ 6 Liverpool Ocular Oncology Research Group, Department of Molecular and Clinical Cancer Medicine, \\ Institute of Systems, Molecular and Integrative Biology, University of Liverpool, Liverpool L7 8TX, UK; \\ H.Kalirai@liverpool.ac.uk (H.K.); s.e.coupland@liverpool.ac.uk (S.E.C.) \\ 7 Unit of Cardiovascular Medicine, Division of Diagnostics and Specialist Medicine, Department of Health, \\ Medical and Caring Sciences, Linköping University, SE-581 83 Linköping, Sweden; \\ mayhe436@student.liu.se (M.H.); lasse.jensen@liu.se (L.D.J.) \\ 8 Xenopat S.L., Parc Científic de Barcelona, Baldiri Reixac, 15-21 Edifici Hèlix, 08028 Barcelona, Spain; \\ rosa.bosch@xenopat.com (R.B.); anna.portela@xenopat.com (A.P.); alberto.villanueva@xenopat.com (A.V.) \\ 9 Medical Oncology Department, Catalan Institute of Cancer (ICO), IDIBELL-OncoBell, Hospitalet de \\ Llobregat, 08908 Barcelona, Spain; jmpiulats@iconcologia.net \\ 10 Clinical Research in Solid Tumors Group (CREST), Bellvitge Biomedical Research Institute \\ IDIBELL-OncoBell, CIBERONC, Hospitalet de Llobregat, 08908 Barcelona, Spain \\ 11 Liverpool Clinical Laboratories, Liverpool University Hospitals NHS Foundation Trust, \\ Liverpool L69 3GA, UK \\ * Correspondence: brendan.kennedy@ucd.ie
}

Received: 20 August 2020; Accepted: 5 October 2020; Published: 13 October 2020

Simple Summary: This research investigates the disease relevance and therapeutic potential of cysteinyl leukotriene receptors in uveal melanoma (UM), a rare eye cancer that often spreads to the liver. Unfortunately, there are no therapies available to stop the spread of UM and patients are often faced with an extremely poor prognosis. We assess whether the cysteinyl leukotriene receptors $\left(\right.$ CysLT $_{1}$ and CysLT $\left._{2}\right)$ are relevant to the progression of UM. Using UM patient samples, we identified that increased levels of CysLT $_{1}$ in tumours is associated with reduced patient survival. Using UM cell lines and zebrafish models, we found that drugs targeting $\mathrm{CysLT}_{1}$, but not $\mathrm{CysLT}_{2}$, can alter hallmarks of cancer including cell growth, proliferation, and metabolism. This study is the first to 
examine the relationship of the CysLT receptors with clinical features of UM. Our data strengthen the importance of CysLT signalling in UM and suggest that antagonism of CysLT 1 may be of therapeutic interest in the disease.

Abstract: Metastatic uveal melanoma (UM) is a rare, but often lethal, form of ocular cancer arising from melanocytes within the uveal tract. UM has a high propensity to spread hematogenously to the liver, with up to $50 \%$ of patients developing liver metastases. Unfortunately, once liver metastasis occurs, patient prognosis is extremely poor with as few as $8 \%$ of patients surviving beyond two years. There are no standard-of-care therapies available for the treatment of metastatic UM, hence it is a clinical area of urgent unmet need. Here, the clinical relevance and therapeutic potential of cysteinyl leukotriene receptors $\left(\mathrm{CysLT}_{1}\right.$ and $\left.\mathrm{CysLT}_{2}\right)$ in $\mathrm{UM}$ was evaluated. High expression of CYSLTR1 or CYSLTR2 transcripts is significantly associated with poor disease-free survival and poor overall survival in UM patients. Digital pathology analysis identified that high expression of $\mathrm{CysLT}_{1}$ in primary UM is associated with reduced disease-specific survival ( $p=0.012 ; \mathrm{HR} 2.76 ; 95 \% \mathrm{CI}$ 1.21-6.3) and overall survival ( $p=0.011$; HR 1.46; 95\% CI 0.67-3.17). High CysLT 1 expression shows a statistically significant $(p=0.041)$ correlation with ciliary body involvement, a poor prognostic indicator in UM. Small molecule drugs targeting $\mathrm{CysLT}_{1}$ were vastly superior at exerting anti-cancer phenotypes in UM cell lines and zebrafish xenografts than drugs targeting $\mathrm{CysLT}_{2}$. Quininib, a selective CysLT $_{1}$ antagonist, significantly inhibits survival $(p<0.0001)$, long-term proliferation $(p<0.0001)$, and oxidative phosphorylation $(p<0.001)$, but not glycolysis, in primary and metastatic UM cell lines. Quininib exerts opposing effects on the secretion of inflammatory markers in primary versus metastatic UM cell lines. Quininib significantly downregulated IL-2 and IL-6 in Mel285 cells $(p<0.05)$ but significantly upregulated IL-10, IL-1 $\beta$, IL-2 $(p<0.0001)$, IL-13, IL-8 $(p<0.001)$, IL-12p70 and IL-6 $(p<0.05)$ in OMM2.5 cells. Finally, quininib significantly inhibits tumour growth in orthotopic zebrafish xenograft models of UM. These preclinical data suggest that antagonism of CysLT $_{1}$, but not CysLT 2 , may be of therapeutic interest in the treatment of UM.

Keywords: uveal melanoma; cysteinyl leukotriene receptors; patient survival; G protein-coupled receptors; angiogenesis; inflammation; metabolism; zebrafish xenograft models

\section{Introduction}

Uveal melanoma (UM) is a rare, intraocular cancer that metastasises predominantly to the liver in approximately $50 \%$ of patients. The primary ocular tumour is usually successfully treated with surgery or radiotherapy [1,2]. However, these treatments have limited success in halting metastatic spread of the disease. Once the cancer has disseminated to the liver, there are limited options available to patients. Overall survival for patients with metastatic UM ranges from 4 to 18 months [3-6]. UM develops in one of the most capillary-rich tissues of the body and is spread solely through the blood stream, suggesting that angiogenesis and vascular invasion play important roles in UM progression.

In comparison to other solid tumours and skin melanomas, UM has a low mutational burden $[7,8]$ making the disease less sensitive to checkpoint inhibitors. The lack of identified mutations in UM narrows the scope for targeted therapies, with no successful targeted therapies available to date [9]. Activating mutations in GNAQ or GNA11 are found in $>80 \%$ of all UMs [10], with mutations in CYSLTR2 or PLCB4 likely to account for an additional 8-10\% of activating UM mutations [11]. These mutations are mutually exclusive and operate in the same pathway [12], highlighting the importance of $\mathrm{CysLT}_{2} / \mathrm{G}_{\alpha \mathrm{q} / 11} / \mathrm{PLCB} 4$ signalling in UM oncogenesis. In contrast to cutaneous melanoma [13], targeted therapies for UM, including those targeting the $\mathrm{CysLT}_{2} / \mathrm{G}_{\alpha \mathrm{q} / 11} / \mathrm{PLCB} 4$ downstream pathways, such as MEK and AKT, failed in early clinical studies [14,15]. 
Synthesised through the 5-lipoxygenase (5-LO) pathway, the cysteinyl leukotrienes (CysLTs), $\mathrm{LTC}_{4}, \mathrm{LTD}_{4}$, and $\mathrm{LTE}_{4}$, are lipid-signalling molecules that mediate acute and chronic inflammation [16]. The CysLTs exert their biological effects via binding to the $G$ protein-coupled receptors (GPCRs), $\mathrm{CysLT}_{1}$ and CysLT 2 . LTD 4 binds to CysLT 1 with high affinity [17], while both $\mathrm{LTD}_{4}$ and $\mathrm{LTC}_{4}$ bind to CysLT with equal affinity [18]. Although activation of both receptors stimulates similar downstream signalling events (calcium flux and accumulation of inositol phosphate) $[17,18]$, the receptors are not functionally redundant [19]. Each receptor has a distinct pattern of cellular and tissue expression [17,18], which in combination with their differing sensitivities to endogenous leukotriene ligands, suggests that each receptor has an individual role in physiology and pathology [20]. Cross-regulation occurs between the receptors: $\mathrm{CysLT}_{2}$ controls the membrane expression of $\mathrm{CysLT}_{1}$ and negatively regulates signalling through CysLT 1 [19].

CysLTs are well known for their role in inflammation, particularly in asthma and allergic rhinitis. Recently, however, a role for CysLTs in cancer has emerged [9,21], with a particular focus on their role in vascular permeability and angiogenesis [22]. In a retrospective analysis, $\mathrm{CysLT}_{1}$ antagonists, montelukast and zafirlukast, display a dose-dependent chemopreventative effect against 14 different cancers [23]. Furthermore, overexpression of $\mathrm{CysLT}_{1}$ is a feature of colorectal cancer, prostate cancer, renal cell carcinoma, urothelial transitional cell carcinoma, and testicular cancer [24-27]. Interestingly, colorectal and breast cancer patients with high expression of $\mathrm{CysLT}_{1}$ have a poor prognosis and reduced survival, respectively $[28,29]$. In contrast, a recurrent, hotspot mutation in CYSLTR2 is a driver oncogene in a small subset of UM [12]. This mutation encodes a p.Leu129Gln substitution, which leads to constitutive activation of endogenous $G_{\alpha q}$ signalling and promotes tumorigenesis in vivo [12]. The same Leu129Gln hotspot mutation in CYSLTR2 has also been identified in blue nevi [30], and in leptomeningeal melanocytic tumours [31] confirming the oncogenic properties of constitutively active signalling through this receptor.

Quininib, a CysLT 1 antagonist, and its analogue, 1,4-dihydroxy quininib, are anti-inflammatory and anti-angiogenic drugs $[32,33]$ with anti-cancer activity in human ex vivo colorectal cancer patient tumour explants and colorectal cancer xenograft models [34,35]. Angiogenesis plays an important role in the development and progression of UM, however the efficacy of anti-angiogenic therapies remains inadequate [36]. In addition, highly vascularised UM are more aggressive and convey a worse prognosis $[37,38]$. This, coupled with the finding that CYSLTR2 acts as an oncogene in a subset of UM, led us to hypothesise that CysLT receptors represent a therapeutic target for UM. To our knowledge, this is the first study to examine the clinical significance of CysLT receptor gene and protein expression in UM patients as the association between the expression of CysLT receptors in primary UM samples and the associated clinical features has not been previously reported. Critically, we find that high expression of CYSLTR1 and CYSLTR2 transcripts correlate with reduced disease-free survival and reduced overall survival in UM patients. We show that both CysLT receptors are expressed in primary $\mathrm{UM}$, and that high expression of $\mathrm{CysLT}_{1}$ is linked to ciliary body involvement, a poor prognostic indicator in UM. Additionally, high expression of $\mathrm{CysLT}_{1}$ in primary UM is significantly associated with reduced melanoma-specific survival and overall survival. CysLT 1 antagonists alter survival, long-term proliferation, metabolism, and the secretion of pro-inflammatory and pro-angiogenic factors in in vitro UM cell line models and can promote anti-cancer activity in in vivo zebrafish xenograft models of UM. This study reinforces the importance of the CysLT $\mathrm{L}_{1 / 2}$ pathway in $\mathrm{UM}$ and suggests that inhibition of $\mathrm{CysLT}_{1}$ represents an alternative therapeutic target for $\mathrm{UM}$.

\section{Results}

\subsection{Analysis of Cysteinyl Leukotriene Receptor Expression in Primary Uveal Melanoma Patient Samples}

The Cancer Genome Atlas (TCGA) contains gene expression data on 80 primary UM samples. Both CysLT receptor genes were expressed in the UM samples confirming their potential disease relevance. Cox survival analysis revealed expression of CYSLTR1 and CYSLTR2 genes are significantly 
associated with disease-free survival ( $p=0.03$; HR 1.05; 95\% CI 1.03-1.07 and $p=0.02$; HR 1.35; 95\% CI 1.25-1.45, respectively) (Figure 1A,D) and overall survival ( $p=0.002$; HR 1.06; 95\% CI 1.04-1.08) (Figure 1B) in UM patients. To resolve a violation of the proportional hazard assumption, the association between CYSLTR2 gene expression and overall survival (Figure 1E) was stratified by time from 0 to 20 months and beyond 20 months and analysed by the likelihood ratio (LHR) test. Expression of CYSLTR2 is significantly associated with overall survival ( $p=0.0001$; HR 1.01; 95\% CI 1-1.02) (Figure 1E). When stratified based on high versus low expression of the receptors, all Kaplan-Meier curves showed significant results. This suggests that UM patients with high CYSLTR1 or CYSLTR2 transcript expression have a worse prognosis than those with low expression of the receptors. TCGA-UM samples were then divided into high and low expression of CYSLTR1 and CYSLTR2 using the third quartile as cut-off and interrogated for their association with pathways of interest using the Molecular Signatures Database (MSigDB). Using Gene Set Variation Analysis, enrichment scores were calculated for the association between high expression of either receptor and pathways of interest. Colour values correspond to the median values of the enrichment scores. Samples expressing high CYSLTR1 showed a significantly altered expression of profiles relating to Inflammatory Response, IFN- $\gamma$, TNF- $\alpha$, Angiogenesis, and GPCR signalling (Figure 1C). Interestingly, the same profiles plus glycolysis showed an altered expression in samples with high expression of CYSLTR2 (Figure 1F).

A

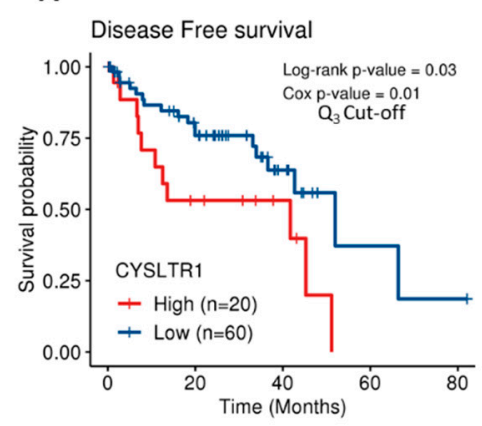

D

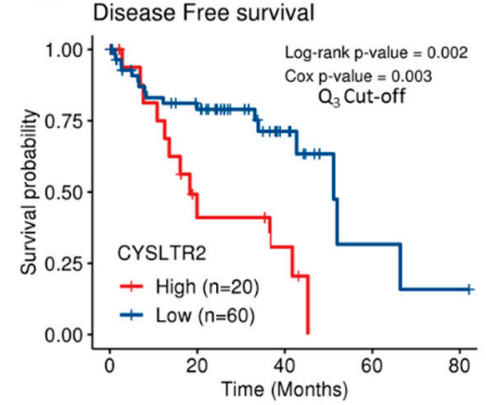

B

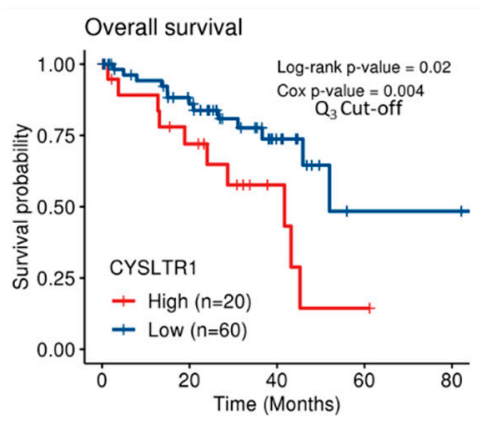

E

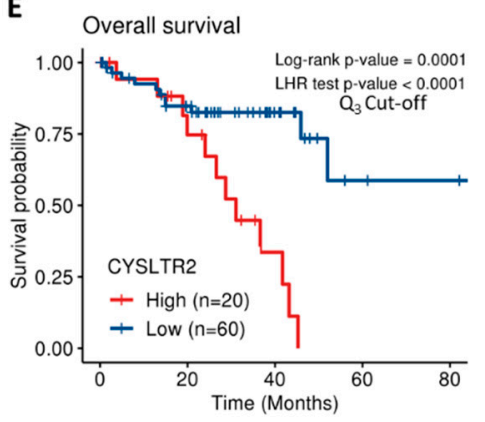

C CYSLTR1
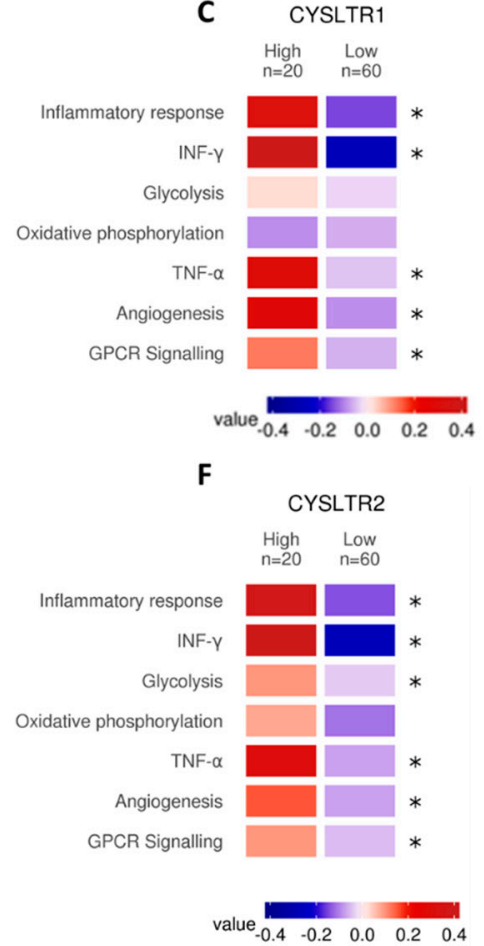

Figure 1. Analysis of CYSLTR1/CYSLTR2 expression and UM patient survival from The Cancer Genome Atlas (TCGA). Kaplan-Meier survival curves demonstrate a statistically significant relationship between high (red) CYSLTR1 expression and disease-free survival (A) $(n=80 ;$ Log-rank; $p=0.03 ;$ HR 1.05; 95\% CI 1.03-1.07) or overall survival (B) ( $n=80$; Log-rank; $p=0.02$; HR 1.06; 95\% CI 1.04-1.08) in UM patients. Low CYSLTR1 expression is shown in blue. Similarly, Kaplan-Meier survival curves demonstrate a statistically significant relationship between high (red) CYSLTR2 expression and disease-free survival (D) ( $n=80$; Log-rank; $p=0.002 ;$ HR 1.35; 95\% CI 1.25-1.45), or overall survival (E) ( $n=80 ;$ Log-rank; $p=0.0001$; HR 1.01; 95\% CI 1-1.02) in UM patients. Low CYSLTR2 expression is shown in blue. The third quartile was used as the cut-off point for high versus low expression for all Kaplan-Meier survival curves. 
Both Log-rank $p$-values (categorical variable) and Cox $p$-values (continuous variable) were calculated and are displayed for (A,B,D). Log-rank and likelihood ratio (LHR) test $p$-values were calculated and are displayed for (E). Samples were scored using gene expression profiles and categorized into high and low CYSLTR1 (C) and CYSLTR2 (F) expression using the third quartile as cut-off. Expression profiles of interest were manually selected from the Molecular Signatures Database (MSigDB) which includes gene sets from Hallmarks and Biocarta curated pathways. Colour values correspond to the median values of the enrichment scores. Patient tumours with high expression of CYSLTR1 show a corresponding significantly altered expression for the terms corresponding to Inflammatory Response, INF- $\gamma$, TNF- $\alpha$, Angiogenesis and GPCR signalling (C) $\left({ }^{*} p<0.05\right)$. Samples with high expression of CYSLTR2 show an associated significantly altered expression for the terms Inflammatory Response, IFN- $\gamma$, Glycolysis, TNF- $\alpha$, Angiogenesis and GPCR signalling $(\mathbf{F})\left({ }^{*} p<0.05\right)$. Differences were assessed using a non-parametric Wilcoxon test. Differences were considered statistically significant when $p$-value $<0.05$.

MCP-counter was used to impute an estimated score for the contribution of infiltrated stromal and immune cells in TCGA samples. A positive correlation was identified between CYSTLR1/CYSTLR2 expression and the presence of immune cells, and the ESTIMATE tool was used to calculate a global score for stromal infiltration. When the models were adjusted by the stromal infiltration scores from ESTIMATE, there was no statistically significant relationship between high CYSLTR1 expression and disease-free survival (Figure S1A) or overall survival (Figure S1B) ( $p=0.57$ and $p=0.075$, respectively). However, high expression of CYSLTR2 maintains a statistically significant relationship with disease-free survival (Figure S1C) and overall survival (Figure S1D) ( $p=0.004$ and $p=0.00027$, respectively). This suggests that tumour infiltrate may contribute to high CYSLTR1 expression in UM patients with reduced survival.

Following analysis of gene expression profiles for both receptors, we examined the protein expression and localisation in an independent cohort of patients. The clinical relevance of CysLT receptors in UM was evaluated by analysing the expression of $\mathrm{CysLT}_{1}$ and $\mathrm{CysLT}_{2}$ proteins in a tissue microarray (TMA) generated from primary UM of 52 consented patients treated at the Liverpool Ocular Oncology Centre.

Of these 52 patients, 26 were males and 26 females, with a median age of 62 years at primary management (range, 39-89). Survival data were not available for one patient, which reduced the numbers available for survival analysis to 51 patients. At the time of study end (29 May 2019), 18/51 UM patients were alive (35.29\%), 25/51 had died from metastatic disease $(49.02 \%)$, and $8 / 25$ had died from other causes (15.69\%). The median survival time was 8 years (range, $0.4-19$ years). The median largest ultrasound tumour diameter was $17.35 \mathrm{~mm}$ (range, 10.6-23.6 mm) with a median ultrasound tumour height of $8 \mathrm{~mm}$ (range, 5-18 mm) (Figure S2C). Epithelioid cells were present in 30/52 (57.69\%) of UM cases; 15/52 (28.85\%) tumours involved the ciliary body and 3/52 (5.78\%) had extraocular extension (Figure S2D).

To conduct manual analysis for both $\mathrm{CysLT}_{1}$ and $\mathrm{CysLT}_{2}$, scores were assigned based on staining intensity (Figure 2A,D), and the percentage of tumour cells stained combined. Using the median as a cut off, a score of 0-7 was designated as low CysLT $1 / 2$ expression, while a score of $<7-12$ was designated as high $\mathrm{CysLT}_{1 / 2}$ expression. In Kaplan-Meier survival curves generated from median scoring of all primary UM cases, immunohistochemical levels of $\mathrm{CysLT}_{1}$ or $\mathrm{CysLT}_{2}$ did not demonstrate a significant association with patient survival from metastatic disease $\left(\mathrm{CysLT}_{1} p=0.122\right.$; HR 2.04; 95\% CI 0.81-5.12, CysLT $2 p=0.341$; HR 1.15; 95\% CI 0.58-2.28) (Figure 2B,E, respectively). However, high $\mathrm{CysLT}_{1}$ expression showed a robust trend towards reduced patient survival (Figure 2B). In agreement with TCGA data, manual analysis of the UM TMA at the median cut-off revealed a statistically significant relationship between high $\mathrm{CysLT}_{1}$ expression and overall survival in UM patients ( $p=0.034$; HR 2.34; 95\% CI 1.04-5.25) (Figure 2C). High CysLT 1 expression also had a statistically significant relationship with ciliary body involvement in the UM patient cohort $(p=0.041)$ (Figure S2D). Ciliary body involvement is a feature of the disease associated with metastatic risk 
and poor patient prognosis $[39,40]$. High expression of CysLT 2 was not significantly associated with overall survival ( $p=0.697$; HR 1.15; 95\% CI 0.58-2.28) (Figure 2F). There was no statistically significant relationship between high or low $\mathrm{CysLT}_{1}$ expression and other clinical features of disease (extraocular extension, monosomy 3, periodic acid-Schiff positive loops, or epithelioid cell morphology) examined (Figure S2D). Manual analysis did not identify a statistically significant relationship between high or low CysLT $_{2}$ expression and clinical features of the disease examined (Figure S2D).
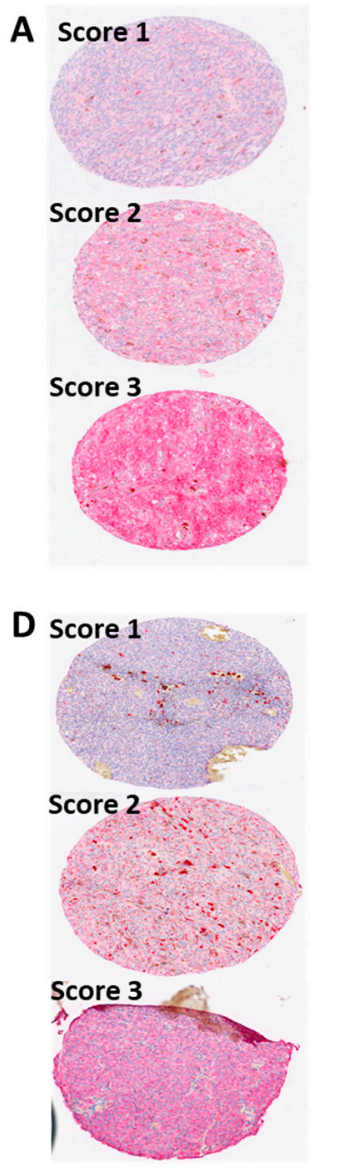

B

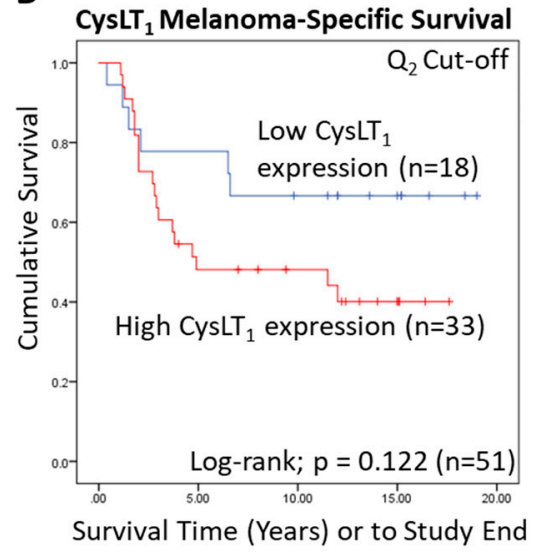

E

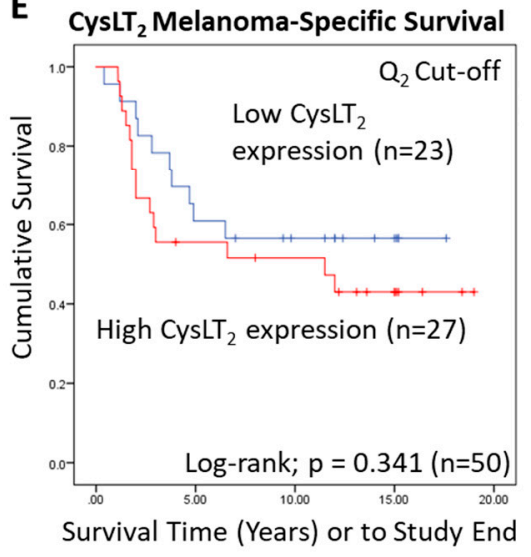

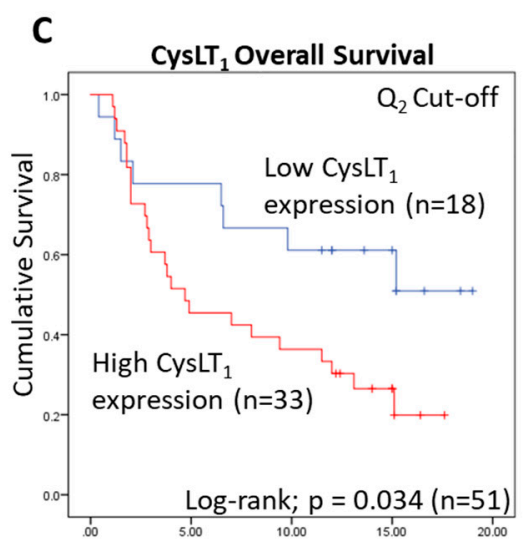

Survival Time (Years) or to Study End

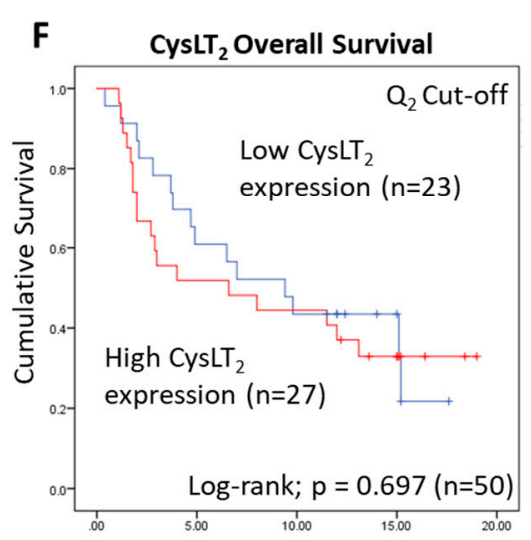

Survival Time (Years) or to Study End

Figure 2. Examination of the prognostic value of $\mathrm{CysLT}_{1}$ and $\mathrm{CysLT}_{2}$ protein expression in primary UM samples by manual pathology. (A) Representative cores from the UM patient TMA designated with a score of 1, 2, or 3 for CysLT $_{1}$ staining intensity. (B) Kaplan-Meier survival curve stratified based by high (red) or low (blue) CysLT $_{1}$ expression and death by metastatic melanoma ( $n=51$; Log-rank; $p=0.122$; HR 2.04; 95\% CI 0.81-5.12). (C) High expression of CysLT $_{1}$ (red) is significantly associated with reduced overall survival in primary UM patients $(n=51$; Log- rank; $p=0.034 ; \mathrm{HR} 2.34 ; 95 \% \mathrm{CI}$ 1.04-5.25) (D) Representative cores from the TMA designated with a score of 1, 2 or 3 for CysLT $_{2}$ staining intensity. (E). Kaplan-Meier survival curve stratified based by high (red) or low (blue) $\mathrm{CysLT}_{2}$ expression and death by metastatic melanoma ( $n=50$; Log-rank; $p=0.341$; HR 1.15, 95\% CI 0.58-2.28). (F) Kaplan-Meier survival curve stratified based by high (red) or low (blue) CysLT 2 expression and death by any cause ( $n=50$; Log-rank; $p=0.697$; HR 1.15; 95\% CI 0.58-2.28). The median was used as the cut-off point for high versus low expression for all Kaplan-Meier survival curves. Number of events indicates the number of deaths due to metastatic melanoma (B,E). Number of events indicates the number of deaths due to any cause $(\mathbf{C}, \mathbf{F})$.

A wider scoring range achieved by digital pathology analysis of this TMA (Figure 3A) strengthened the relationship between high CysLT $_{1}$ expression and patient survival. With a 3rd quartile segregation, high expression of $\mathrm{CysLT}_{1}$ is significantly associated with reduced melanoma-specific survival ( $p=0.0012$; HR 2.76; 95\% CI 1.21-6.3) and reduced overall survival ( $p=0.0011$; HR 2.76; 95\% CI 
1.21-6.3) in this primary UM cohort (Figure 3B,C, respectively). In agreement with manual analysis, there was no significant relationship between $\mathrm{CysLT}_{2}$ expression and patient outcomes (Figure $3 \mathrm{E}, \mathrm{F}$ ).

A

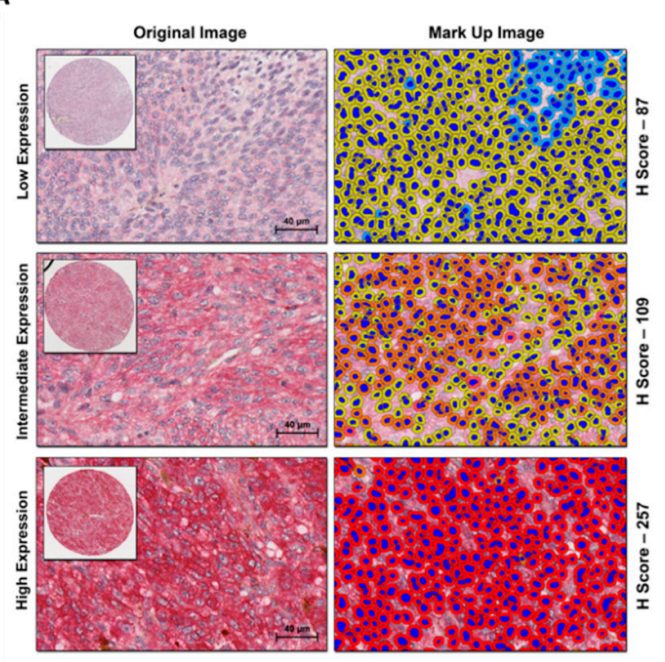

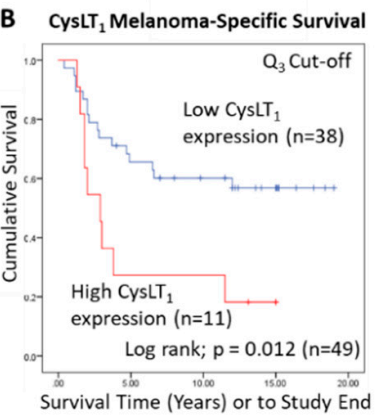

D

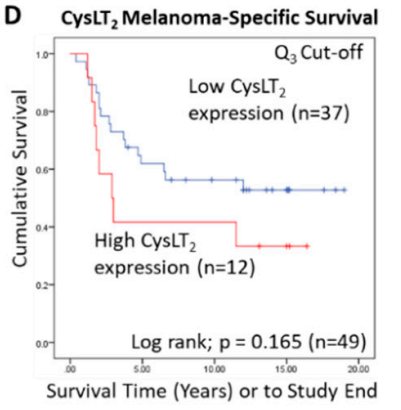

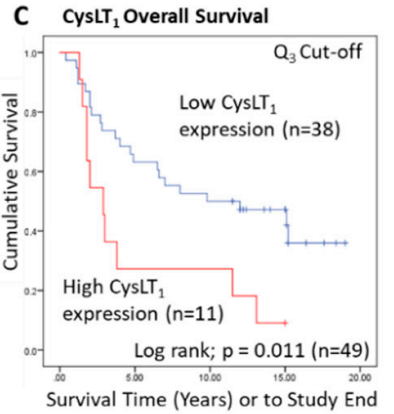

E CysLT, Overall Survival

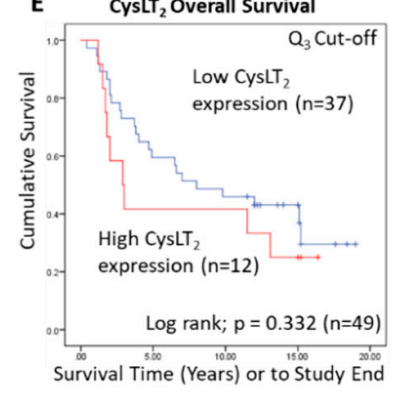

Figure 3. Examination of the prognostic value of $\mathrm{CysLT}_{1}$ and $\mathrm{CysLT}_{2}$ protein expression in primary UM patient samples by digital pathology analysis. (A) Representative cores from the UM TMA designated with a score of Low, Intermediate, or High expression for CysLT $_{1}$ staining following digital analysis $($ Scale $=40 \mu \mathrm{m})$. (B) High expression of CysLT $_{1}$ (red) is associated with reduced survival from metastatic melanoma in primary UM patients ( $n=49$; Log-rank; $p=0.012$; HR 2.755; 95\% CI 1.205-6.3) (C) High expression of $\mathrm{CysLT}_{1}$ (red) is associated with reduced overall survival in primary UM patients $(n=49$; Log-rank; $p=0.011$; HR 2.755; 95\% CI 1.205-6.3) (D) Kaplan-Meier survival curve stratified based by high (red) or low (blue) CysLT 2 expression and death by metastatic melanoma $(n=49$; Log-rank; $p$ $=0.165 ;$ HR 1.796; 95\% CI 0.773-4.172). (E) Kaplan-Meier survival curve stratified based by high (red) or low (blue) CysLT $_{2}$ expression and death by any cause $(n=50$; Log-rank; $p=0.332 ;$ HR $1.461 ; 95 \%$ CI 0.674-3.167). The third quartile was used as the cut-off point for high versus low expression for all Kaplan-Meier survival curves. Number of events indicates the number of deaths due to metastatic melanoma (B,D). Number of events indicates the number of deaths due to any cause $(\mathbf{C}, \mathbf{E})$.

Gene expression data from TCGA suggest that high expression of CYSLTR2 is significantly linked to overall survival in UM patients. This was not supported by the data generated at the protein level using the UM patient TMA. Data from both TCGA and the UM patient TMA suggest a link between high $\mathrm{CysLT}_{1}$ expression and patient survival. A significant relationship between high $\mathrm{CysLT}_{1}$ expression and melanoma-specific survival, as well as overall survival, was confirmed by this data. Interestingly, high expression of CysLT $_{1}$ was significantly associated with ciliary body involvement, further suggesting a potential link between receptor expression and patient prognosis.

\subsection{Cysteinyl Leukotriene Receptors are Expressed in Primary and Metastatic Human Uveal Melanoma Cell Lines}

To use UM cell lines as in vitro models to investigate the anti-cancer potential of drugs modulating CysLT signalling, we analysed the endogenous expression levels of CysLT 1 and $\mathrm{CysLT}_{2}$ receptors between primary versus metastatic UM cell lines (Figure 4). Mel285 and Mel270 are derived from primary choroidal melanomas and OMM2.5 is derived from a liver metastasis of the same patient as Mel270 [41]. Both Mel270 and OMM2.5 are GNAQ Q209P positive cell lines, while Mel285 is negative for both GNAQ and GNA11 mutations (Figure 4E) [41]. Real-time PCR confirmed that transcripts for 
CysLT $_{1}$ and CysLT $_{2}$ are abundantly expressed in all three cell lines with no significant differences in expression levels detected (Figure 4A,B). By Western blotting, prominent 38.5 and $39.6 \mathrm{kDa}$ bands were detected for $\mathrm{CysLT}_{1}$ and $\mathrm{CysLT}_{2}$, respectively, in each cell line (Figure 4C,D). These data confirmed that Mel270, Mel285, and OMM2.5 cell lines were appropriate to analyse the effects of CysLT receptor antagonists on UM cancer hallmarks in vitro.

A

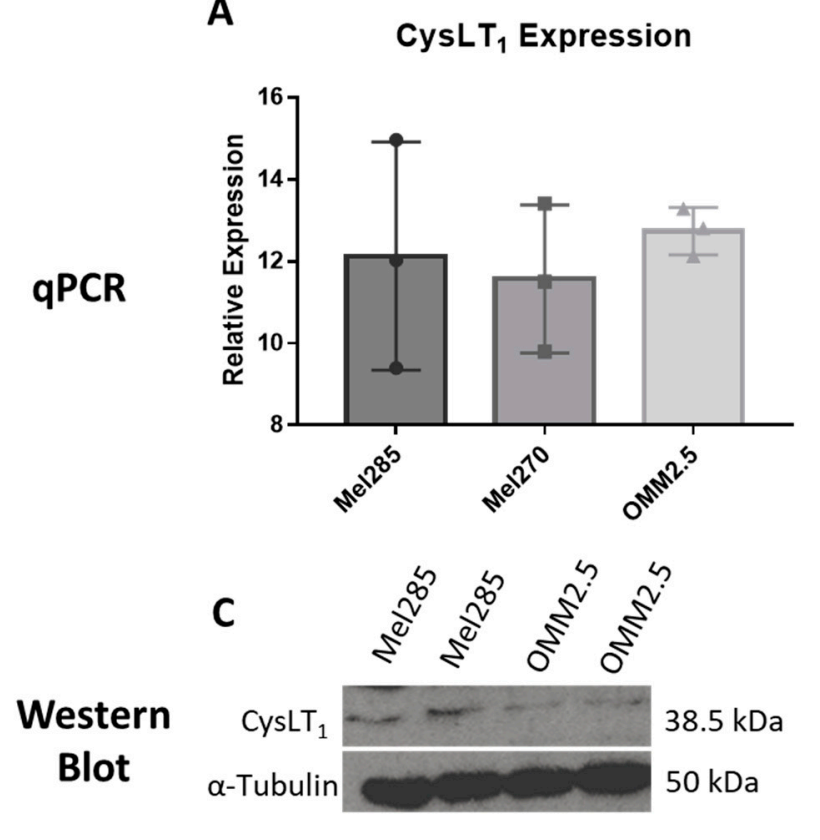

B
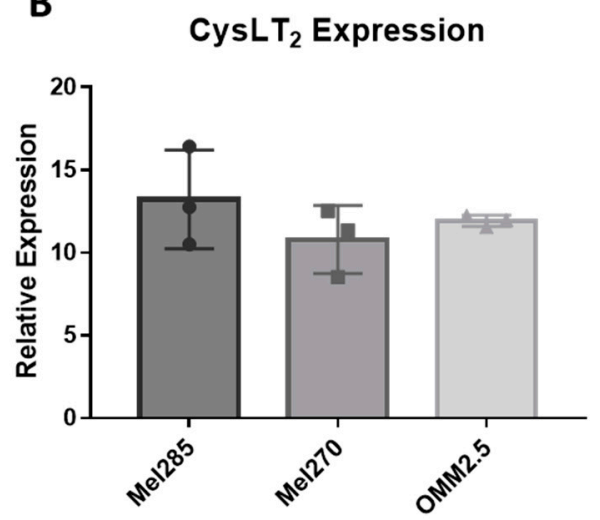

D
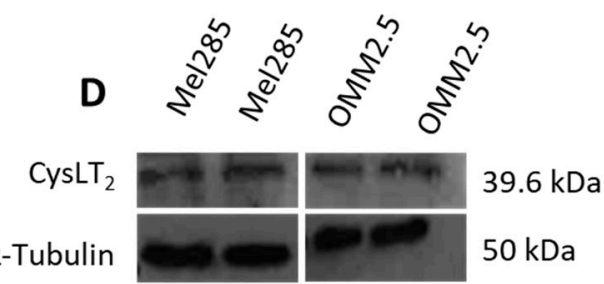

\section{E}

\begin{tabular}{|l|l|l|l|}
\hline & Mel270 & Mel285 & OMM2.5 \\
\hline Primary/Metastatic & Primary & Primary & Metastatic \\
\hline Mutation & GNAQ Q209P & Unknown & GNAQ Q209P \\
\hline Sex of patient & Male & Female & Male \\
\hline BAP1 status & WT & WT & WT \\
\hline
\end{tabular}

Figure 4. CysLT $_{1}$ and $\mathrm{CysLT}_{2}$ are expressed in uveal melanoma cell lines. qPCR analysis confirmed the expression of $\mathrm{CysLT}_{1}$ (A) and CysLT 2 (B) mRNA in UM cell lines, Mel285, Mel270, and OMM2.5 $(n=3)$. Western blot analysis confirmed the expression of $\operatorname{CysLT}_{1}(\mathbf{C})$ and $\mathrm{CysLT}_{2}(\mathbf{D})$ in Mel285 and OMM2.5 cells $(n=2)$. (E) Characteristics of UM cell lines used in this study. Statistical analysis was carried out using a paired $t$-test. Data are expressed as mean + SEM.

2.3. CysLT 1 , But Not CysLT 2 , Targeting Drugs Reduce Uveal Melanoma Cell Number in a Time- and DoseDependent Manner

CysLT receptors activate downstream pathways associated with cell survival and proliferation [42]. Thus, we investigated if CysLT receptor antagonists altered the proliferation of human UM cell lines in vitro. Mel270, Mel285, and OMM2.5 UM cell lines were treated with the CysLT ${ }_{1}$-selective antagonists montelukast [43], quininib [32], 1,4-dihydroxy quininib [35]; the CysLT2-selective antagonist, HAMI 3379 [44]; or dacarbazine, a chemotherapeutic commonly used in the treatment of metastatic UM [45]. In Mel285 cells, after $24 \mathrm{~h}$ of drug treatment, dacarbazine, montelukast, and HAMI 3379 did not significantly reduce UM cell number (Figure 5A). In contrast, quininib and 1,4-dihydroxy quininib resulted in a dose-dependent reduction in Mel285 cell number with $50 \mu \mathrm{M}$ quininib resulting in a $70.8 \%$ reduction in cell number $(p=0.029)$ and $20 \mu \mathrm{M} 1$,4-dihydroxy quininib reducing cell number by 
$61.8 \%(p=0.027)$ after $24 \mathrm{~h}$ (Figure 5A). In Mel285 cells, after $96 \mathrm{~h}$ of drug treatment, dacarbazine and HAMI 3379 still did not significantly reduce UM cell number (Figure 5E). In contrast to $24 \mathrm{~h}$ treatment, $50 \mu \mathrm{M}$ montelukast significantly ( $p=0.0001$ ) reduced ( $84 \%$ reduction) UM cell number (Figure 5E). Quininib and 1,4-dihydroxy quininib reproduced a dose-dependent reduction in Mel285 cell number with $50 \mu \mathrm{M}$ quininib now resulting in $95.1 \%$ reduced cell number $(p=0.0001)$ and $20 \mu \mathrm{M} 1$,4-dihydroxy quininib now reducing cell number by $55.9 \%(p=0.0016)$ after $96 \mathrm{~h}$ (Figure $5 \mathrm{E}$ ).
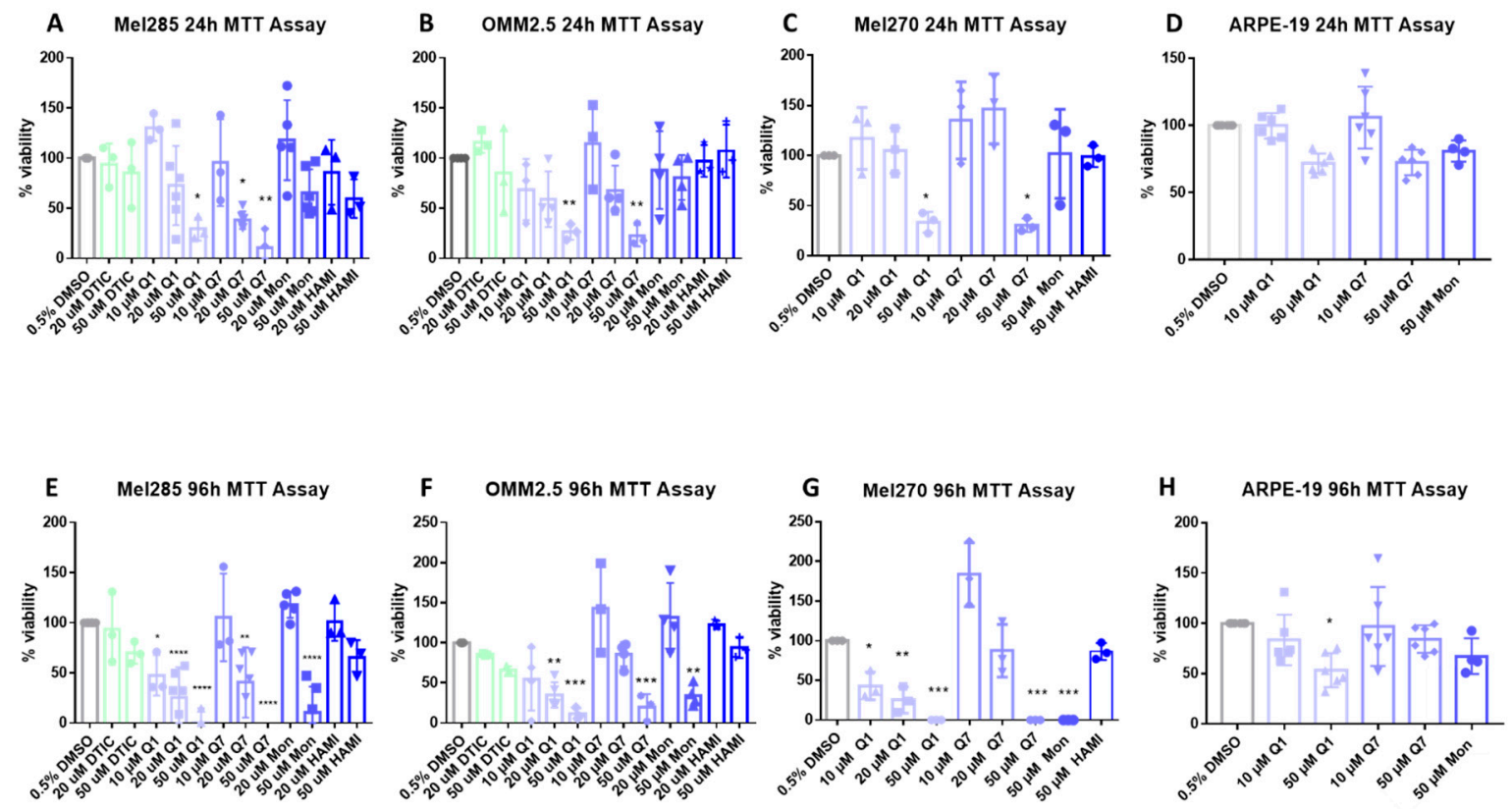

Figure 5. CysLT 1 antagonists reduce cell viability in uveal melanoma cell lines. Graphs represent the effects of treatment with varying concentrations of dacarbazine (DTIC), quininib (Q1), 1,4-dihydroxy quininib (Q7), montelukast (Mon), and HAMI 3379 (HAMI) for 24 and $96 \mathrm{~h}$ in Mel285 (A,E) $(n=3 / n=6)$, OMM2.5 (B,F), $(n=3 / n=4), \operatorname{Mel} 270(\mathbf{C}, \mathbf{G})(n=3)$ and ARPE-19 $(\mathbf{D}, \mathbf{H})(n=4 / n=6)$ cell lines. Treatment with $50 \mu \mathrm{M}$ of quininib, 1,4-dihydroxy quininib, and montelukast for $96 \mathrm{~h}$ significantly reduced cell viability in Mel285 (E), OMM2.5 (F), and Mel270 (G) cells. (D) Quininib analogues had no effect on ARPE-19 cells at 10 or $50 \mu \mathrm{M}$ following 24 treatment. (H) $50 \mu \mathrm{M}$ of quininib reduced ARPE-19 viability at $96 \mathrm{~h}$. Viability of cells was determined using MTT (3-(4,5-dimethylthiazol-2-yl)-2,5-diphenyltetrazolium bromide) assay. 5000 cells were seeded and treated in triplicate for each individual experiment. Statistical analysis was performed by ANOVA with Dunnett's post hoc multiple comparison test. Error bars are mean + S.E. ${ }^{*} p<0.05 ;{ }^{* *} p<0.01 ;{ }^{* * *} p<0.001 ;{ }^{* * * *} p<0.0001$.

In Mel270 cells, after $24 \mathrm{~h}$ of drug treatment, montelukast and HAMI 3379 did not significantly reduce cell number (Figure 5C). Treatment with quininib and 1,4-dihydroxy quininib resulted in a reduction in Mel270 cell number with $50 \mu \mathrm{M}$ quininib reducing cell number by $66.4 \%(p=0.05)$ and $50 \mu \mathrm{M}$ 1,4-dihydroxy quininib reducing cell number by $69.5 \%(p=0.0399)$ (Figure $5 \mathrm{C})$. In Mel270 cells, following $96 \mathrm{~h}$ of drug treatment, HAMI 3379 still failed to significantly reduce cell number (Figure 5G). Treatment with $50 \mu \mathrm{M}$ montelukast, $50 \mu \mathrm{M}$ quininib, and $50 \mu \mathrm{M}$ 1,4-dihydroxy quininib all reduced cell number by $100 \%$ ( $p<0.0001$, for each of the respective treatments) (Figure 5G).

In OMM2.5 cells, a similar trend was observed (Figure 5B,F). Following $24 \mathrm{~h}$ of drug treatment, dacarbazine, montelukast and HAMI 3379 did not significantly reduce cell number (Figure 5B). $50 \mu \mathrm{M}$ of both quininib and 1,4-dihydroxy quininib significantly ( $p=0.0068, p=0.0043$, respectively) reduced (73.5\% and $77.1 \%$ reductions, respectively) cell viability after $24 \mathrm{~h}$ of treatment (Figure 5B). In OMM2.5 cells, after $96 \mathrm{~h}$ of drug treatment, dacarbazine and HAMI 3379 did not significantly reduce cell number. Treatment with $50 \mu \mathrm{M}$ montelukast reduced cell number by $66 \%(p=0.0024)$. Quininib and 1,4-dihydroxy quininib reproduced a dose-dependent reduction in cell number with $50 \mu \mathrm{M}$ quininib 
resulting in an $88.8 \%$ reduction $(p=0.0002)$ and $50 \mu \mathrm{M}$ 1,4-dihydroxy quininib resulting in a $70.4 \%$ reduction $(p=0.0006)$ (Figure 5F).

To determine whether the effect of CysLT 1 antagonists was specific to UM cells, ARPE-19 cells, a non-cancerous human retinal pigment epithelium cell line, was treated as a comparator. Following $24 \mathrm{~h}$ of treatment, in contrast to all three UM cell lines where viability was reduced by $60-70 \%, 50 \mu \mathrm{M}$ quininib or 1,4-dihydroxy quininib did not significantly reduce ( $28 \%$ and $27.5 \%$, respectively) ARPE-19 cell number (Figure 5A-D). Following $96 \mathrm{~h}$ treatment, $10 \mu \mathrm{M}$ quininib or 1,4-dihydroxy quininib did not significantly reduce (17\% and 3.7\%, respectively) ARPE-19 cell number, contrasting with robust effects on viability in UM cells lines (Figure 5D-G). After $96 \mathrm{~h}, 50 \mu \mathrm{M}$ quininib reduced ARPE-19 cell viability by $46.6 \%(p=0.0121$ ) (Figure $5 \mathrm{H})$, compared to a $95.1 \%$ reduced viability observed in Mel285 cells (Figure 5E) and an 88.8\% reduced viability in OMM2.5 cells (Figure 5F).50 $\mu \mathrm{M}$ 1,4-dihydroxy quininib had no significant effect on ARPE-19 cell number at $96 \mathrm{~h}$ (Figure 5H).

Our results suggest that drugs targeting CysLT $_{1}$, but not $\mathrm{CysLT}_{2}$, selectively alter primary and metastatic UM cell number in a time- and dose-dependent manner.

\subsection{Quininib Drugs Inhibit Long-Term Uveal Melanoma Cell Proliferation}

Clonogenic colony formation assays were conducted in Mel285 and OMM2.5 cell lines to determine if CysLT receptor drugs attenuate long-term UM cell proliferation. Mel270 cells failed to grow when seeded at the low cell density required for this assay and as a result, were excluded. UM cells were treated for 24-96 h and grown for 10 additional days prior to analysis of clone survival (Figure 6).

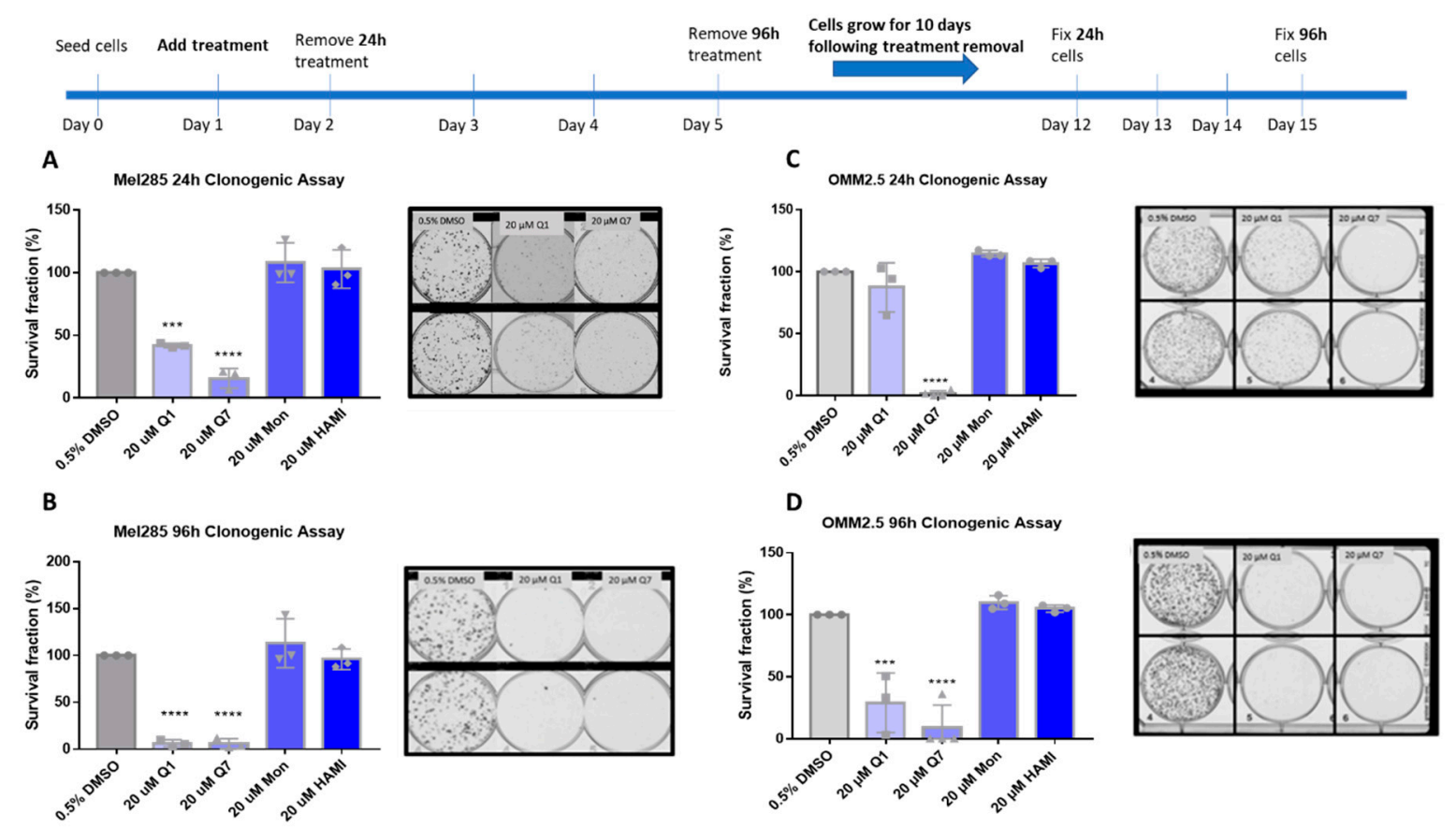

Figure 6. Quininib and 1,4-dihydroxy quininib reduce colony formation in Mel285 and OMM2.5 cells. Graphs show the percentage survival fraction of clones at $24(\mathbf{A}, \mathbf{C})$ and $96 \mathrm{~h}(\mathbf{B}, \mathbf{D})$ post treatment with quininib (Q1), 1,4-dihydroxy quininib (Q7), montelukast (Mon), or HAMI 3379 (HAMI). Images of clones captured by GelCount ${ }^{\mathrm{TM}}$ system (Oxford Optronix) after 10 days of culture following treatment with DMSO control or $20 \mu \mathrm{M}$ quininib (Q1) or $20 \mu \mathrm{M}$ 1,4-dihydroxy quininib (Q7) for 24 or $96 \mathrm{~h}$. Clones were stained with $0.5 \%$ crystal violet before counting. 1500 cells (Mel285) or 9000 cells (OMM2.5) were seeded and treated in duplicate in 6-well plates for each individual experiment and individual experiments were conducted three times $(n=3)$. Statistical analysis was performed by ANOVA with Dunnett's post hoc multiple comparison test. Error bars are mean + S.E. ${ }^{* * *} p<0.001 ;{ }^{* * * *} p<0.0001$. 
In Mel285 cells, UM clone survival after $24 \mathrm{~h}$ treatment was not significantly reduced by treatment with $20 \mu \mathrm{M}$ montelukast or HAMI 3379. $24 \mathrm{~h}$ treatment with quininib significantly reduced clone survival by 58.1\% ( $p=0.0002$ ) (Figure 6A). Likewise, $20 \mu \mathrm{M}$ 1,4-dihroxy quininib significantly reduced Mel285 clone survival by $84.3 \%(p=0.0001)$ after $24 \mathrm{~h}$ treatment.20 $\mu \mathrm{M}$ montelukast or HAMI 3379 failed to significantly reduce clone survival following treatment for $96 \mathrm{~h}$ (Figure 6B). The trend observed with $20 \mu \mathrm{M}$ quininib and 1,4-dihydroxy quininib was reproduced following $96 \mathrm{~h}$ treatment.20 $\mu \mathrm{M}$ quininib reduced clone survival by $93.7 \%(p=0.0001)$ and $20 \mu \mathrm{M} 1$,4-dihydroxy quininib reduced clone survival by $94 \%(p=0.0001)$ (Figure $6 \mathrm{~B}$ ). There was a statistically significant reduction in clone survival in Mel285 cells treated with quininib for $96 \mathrm{~h}$ compared to those treated for $24 \mathrm{~h}(p=0.0064)$ (Figure S3A).

In the metastatic UM cell line OMM2.5, $20 \mu \mathrm{M}$ 1,4-dihydroxy quininib was the only drug to significantly reduce clone survival following $24 \mathrm{~h}$ of treatment $(98.2 \%$ reduction, $p=0.0001)$ (Figure $6 \mathrm{C}$ ). Treatment with $20 \mu \mathrm{M}$ quininib, montelukast or HAMI 3379 for $24 \mathrm{~h}$ did not significantly alter clone survival. In contrast, following $96 \mathrm{~h}$ treatment with quininib a 78.2\% reduction $(p=0.0004)$ was observed (Figure 6D).96 h treatment with 1,4-dihydroxy quininib produced a 91\% reduction $(p=0.0001$ ). Treatment with $20 \mu \mathrm{M}$ montelukast or HAMI 3379 did not significantly alter clone survival in OMM2.5 cells (Figure 6D). Consistent with the Mel285 data, there was a statistically significant decrease in clone survival in OMM2.5 cells treated with quininib for $96 \mathrm{~h}$ when compared to those treated for $24 \mathrm{~h}$ $(p=0.0164)$ (Figure S3B).

Interestingly, there were some significant differences between cell lines. Following $24 \mathrm{~h}$ treatment, $20 \mu \mathrm{M}$ quininib reduced clone survival of Mel285 cells by $58.1 \%$ compared to a non-significant reduction in OMM2.5 cells ( $p=0.0167$ ) (Figure S3C). In contrast, treatment with $20 \mu \mathrm{M}$ 1,4-dihydroxy quininib for $24 \mathrm{~h}$ reduced clone growth by $98.2 \%$ in OMM2.5 cells compared to $84.3 \%$ in Mel285 cells $(p=0.0180)$ (Figure S3C).

In summary, the CysLT 1 -selective antagonists quininib and 1,4-dihydroxy quininib are effective at inhibiting long-term proliferation of primary and metastatic UM cell lines. In both cell lines, quininib is more effective following $96 \mathrm{~h}$ of treatment. In Mel285 cells, $20 \mu \mathrm{M}$ quininib is more effective following $24 \mathrm{~h}$ treatment while in OMM2.5 cells, $20 \mu \mathrm{M}$ 1,4-dihydroxy quininib is more effective following $24 \mathrm{~h}$ treatment.

\subsection{Quininib Drugs Alter the Cancer Secretome of Inflammatory and Angiogenic Factors in Mel285 and OMM2.5 Uveal Melanoma Cell Lines}

We hypothesised that the effects of CysLT receptor drugs on UM cell proliferation and survival may be mediated via modulating angiogenic or inflammatory pathways. Multiplex ELISA quantified whether the secretion of a panel of inflammatory (IFN- $\gamma$, IL-10, IL-12p70, IL-13, IL-1 $\beta$, IL-2, IL-4, IL-6, IL-8, TNF- $\alpha$ ) (Figure 7) and angiogenic markers (bFGF, Flt-1, PIGF, Tie-2, VEGF-C, VEGF-D and VEGF-A) (Figure 8) was altered in conditioned media from Mel285 and OMM2.5 cells treated for $24 \mathrm{~h}$. For both cell lines, secreted PIGF, TIE-2, and VEGF-D were under the level of detection and were removed from analysis. IFN- $\gamma$ and IL-4 secretion were not significantly altered in either cell line following treatment with any tested drugs (Figure S4).

In Mel285 cells, treatment with $20 \mu \mathrm{M}$ quininib significantly reduced secreted levels of IL-2 and IL-6 ( $p=0.0437, p=0.0142$, respectively), and significantly increased secreted levels of bFGF and VEGF-C ( $p=0.0006, p=0.0179$, respectively) (Figures 7 and 8). Treatment with $20 \mu \mathrm{M} 1$,4-dihydroxy quininib in Mel285 cells significantly decreased secreted IL-6 ( $p=0.0048)$, and significantly increased secreted Flt-1 ( $p=0.0014$ ) (Figures 7 and 8). Treatment with $20 \mu \mathrm{M}$ montelukast or $20 \mu \mathrm{M}$ HAMI 3379 showed no statistical difference on the secretion of any inflammatory or angiogenic markers examined in Mel285 UM cells (Figures 7 and 8, Figure S4). 
A
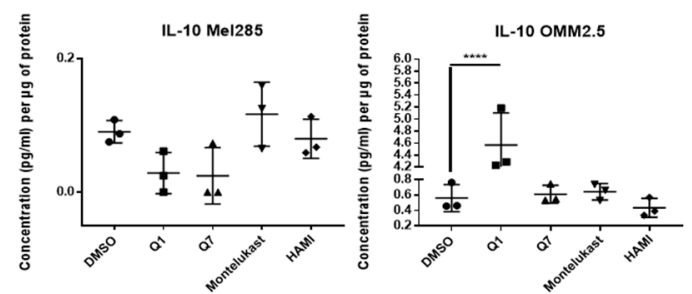

B

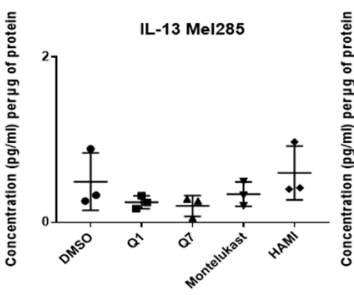

C

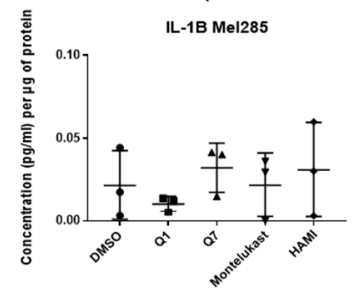

D

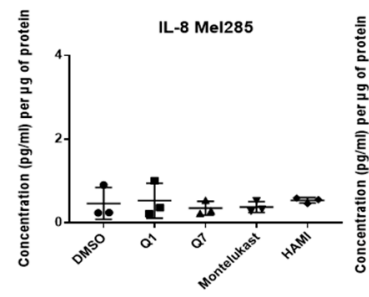

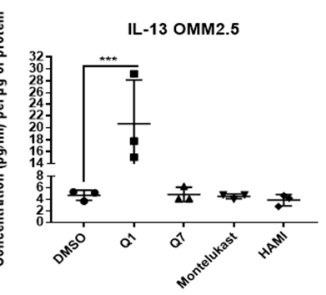
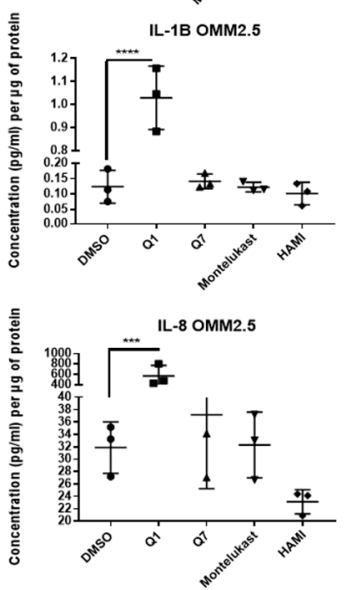

E
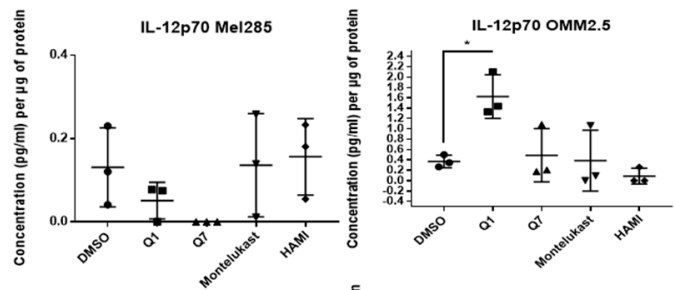

$\mathbf{F}$
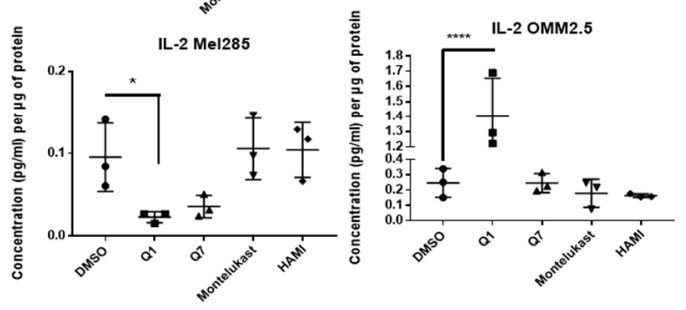

G
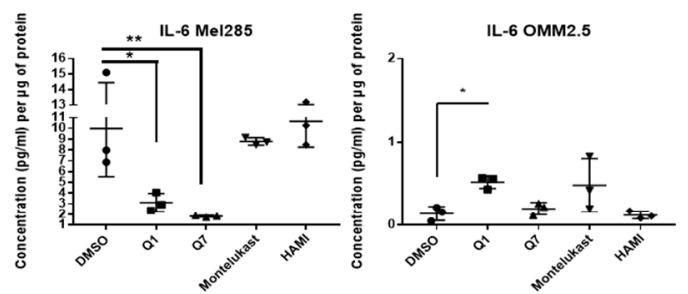

H

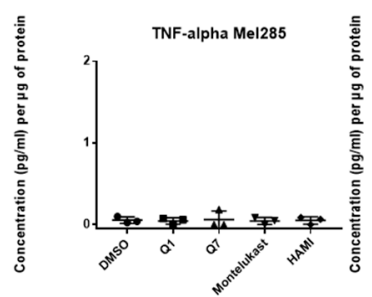

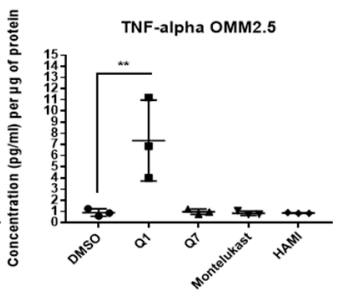

Figure 7. ELISA of cell conditioned media demonstrates that $24 \mathrm{~h}$ treatment with $20 \mu \mathrm{M}$ quininib analogues decreases inflammatory markers in Mel285 cells but increases inflammatory markers in OMM2.5 cells. In OMM2.5 cells, $24 \mathrm{~h}$ treatment with quininib (Q1) significantly increased the secretion of IL-10 (A), IL-13 (B), IL-1B (C), IL-8 (D), IL-12p70 (E), IL-2 (F), IL-6 (G), and TNF- $\alpha$ (H). In Mel285 cells, 24-h treatment with $20 \mu \mathrm{M}$ quininib (Q1) and 1,4-dihydroxy quininib (Q7) significantly reduced the levels of IL-2 (F) and IL-6 (G). Treatment with $20 \mu \mathrm{M}$ montelukast or HAMI 3379 had no effect on the secretion of inflammatory markers in either cell line. Conditioned media were collected from three separate experiments and analysed by ELISA $(n=3)$. All secretions were normalised to total protein content. Statistical analysis was performed by ANOVA with Dunnett's post hoc multiple comparison test. Error bars are mean + S.E. ${ }^{*} p<0.05 ;{ }^{* *} p<0.01 ;^{* * *} p<0.001{ }^{* * * *} p<0.0001$.

In the metastatic OMM2.5 cell line, treatment with $20 \mu \mathrm{M}$ quininib significantly upregulated the secretion of IL-10, IL-1 $\beta$, IL-2 ( $p=0.0001)$, IL-13 ( $p=0.0007)$, IL-8 ( $p=0.001)$, IL-12p70 ( $p=0.0119)$, TNF- $\alpha$ $(p=0.0023)$, IL-6 ( $p=0.0441)$, and Flt-1 ( $p=0.0362)$ (Figure 7). Treatment with $20 \mu \mathrm{M} 1$,4-dihydroxy quininib significantly upregulated the secretion of VEGF-A $(p=0.0183)$ (Figure 8). Again, treatment with $20 \mu \mathrm{M}$ montelukast or $20 \mu \mathrm{M}$ HAMI 3379 showed no statistical difference on the secretion of any inflammatory or angiogenic markers examined in OMM2.5 cells (Figures 7 and 8, Figure S4).

The quininib drugs also produce cell line-dependent effects on the cancer secretome of UM cell lines. For example, in Mel285 cells, quininib decreases the secretion of inflammatory factors (IL-2 and IL-6) and increases the secretion of angiogenic factors (bFGF and VEGF-C). In OMM2.5 cells, a similar upregulation of angiogenic factors was observed following treatment with quininib (Flt- 1 and VEGF-A), but in profound contrast quininib increased the secretion of 8 inflammatory factors (IL-10, IL-12p70, IL-13, IL-1 $\beta$, IL-2, IL-6, IL-8, TNF- $\alpha$ ) in OMM2.5 cells. 
A

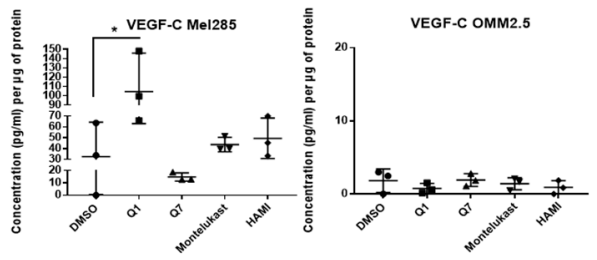

B

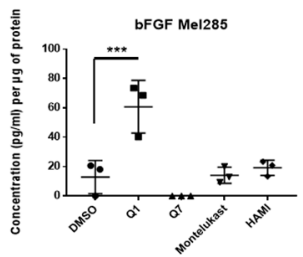

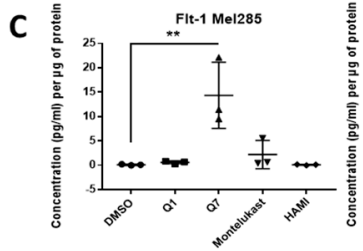
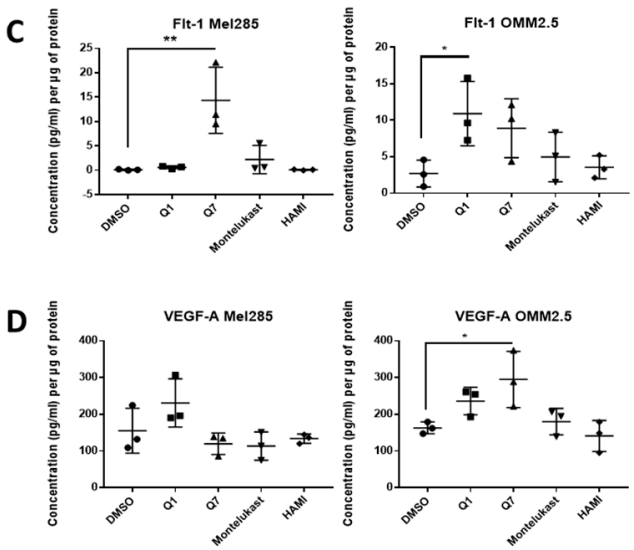

Figure 8. ELISA of cell conditioned media demonstrates that $24 \mathrm{~h}$ treatment with $20 \mu \mathrm{M}$ quininib analogues increases angiogenic markers in Mel285 cells and OMM2.5 cells. In Mel285 cells, $24 \mathrm{~h}$ treatment with $20 \mu \mathrm{M}$ quininib (Q1) significantly increased the secretion of VEGF-C (A) and bFGF (B) Treatment with $20 \mu \mathrm{M}$ 1,4-dihydroxy quininib (Q7) significantly increased the secretion of Flt-1 (C) In OMM2.5 cells, $24 \mathrm{~h}$ treatment with quininib significantly increased the secretion of Flt-1 (C) and VEGF-A (D) Treatment with $20 \mu \mathrm{M}$ montelukast or HAMI 3379 had no effect on the secretion of inflammatory markers in either cell line. Conditioned media were collected from three separate experiments and analysed by ELISA $(n=3)$. All secretions were normalised to total protein content. Statistical analysis was performed by ANOVA with Dunnett's post hoc multiple comparison test. Error bars are mean + S.E. ${ }^{*} p<0.05,{ }^{* *} p<0.01,{ }^{* * *} p<0.001$.

\subsection{CysLT 1 Antagonists Inhibit Oxidative Phosphorylation, But Not Glycolysis, in Uveal Melanoma Cell Lines}

Altered metabolism is a hallmark of cancer [46] and oxidative phosphorylation has emerged as a therapeutic strategy [47]. Comparing 31 tumour types, UM ranked amongst the tumours with the highest oxidative phosphorylation signature [48]. To determine if the effects of CysLT $_{1}$ antagonists were due to altered metabolism in UM cells, the Seahorse Assay was performed assessing two key metabolic pathways: oxidative phosphorylation and glycolysis. Mel285 and OMM2.5 cell lines were treated for $24 \mathrm{~h}$ with $20 \mu \mathrm{M}$ of quininib, 1,4-dihyroxy quininib or montelukast prior to quantification of live metabolic readout. Quininib and 1,4-dihyroxy quininib significantly inhibit oxidative phosphorylation in Mel285 cells ( $p=0.001$ and $p=0.05$, respectively) (Figure 9A). In OMM2.5 cells, quininib, 1,4-dihyroxy quininib and montelukast exert significant inhibitory effects on oxidative phosphorylation $(p=0.01$, $p=0.05$ and $p=0.05$, respectively) (Figure 9G). None of the drugs tested alter the extracellular acidification rate, a measure of glycolysis, in either Mel285 (Figure 9B) or OMM2.5 cells (Figure 9H). In Mel285 cells, quininib and 1,4-dihydroxy quininib significantly alter the OCR:ECAR ratio $(p=0.01)$ (Figure 9C) and reduce basal respiration ( $p=0.01$ and $p=0.05$, respectively) (Figure 9D). In OMM2.5 cells, quininib, 1,4-dihydroxy quininib, and montelukast alter the OCR:ECAR ratio $(p=0.01, p=0.05$ and $p=0.05$, respectively) (Figure 9I), while quininib and 1,4-dihydroxy quininib significantly reduce basal respiration ( $p=0.01$ and $p=0.05$, respectively) (Figure 9J). In Mel285 cells, quininib significantly reduces ATP production ( $p=0.001$ ) (Figure 9E) and maximal respiration $(p=0.001)$ (Figure 9F). Quininib and 1,4-dihydroxy quininib significantly reduce ATP production in OMM2.5 cells $(p=0.01$ and $p=0.05$, respectively) (Figure 9K). Quininib, 1,4-dihydroxy quininib, and montelukast significantly reduce maximal respiration in OMM2.5 cells ( $p=0.001, p=0.05$ and $p=0.05$, respectively) (Figure 9L). Quininib has a significantly greater effect on the reduction of maximal respiration in OMM2.5 cells compared to Mel285 cells $(p<0.05)$. 
Mel285

A

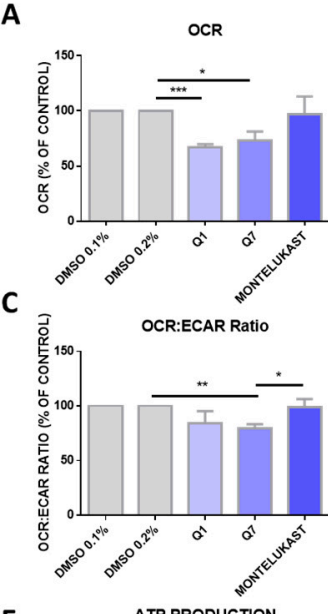

E

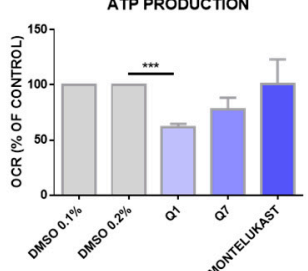

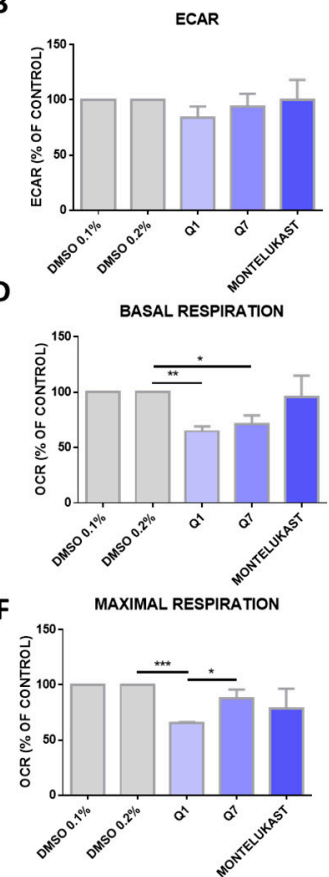

OMM2.5
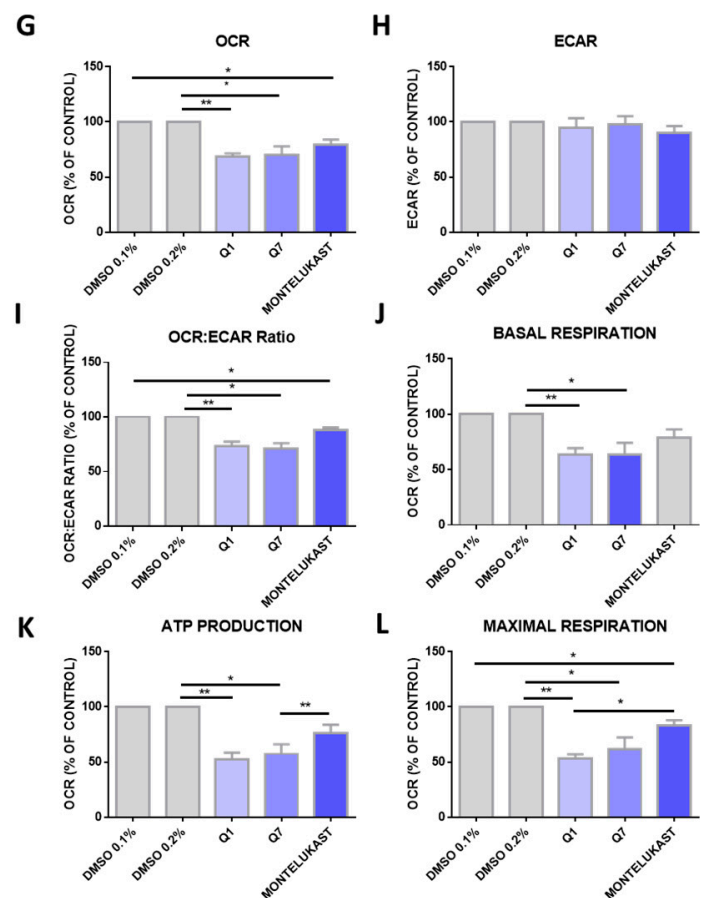

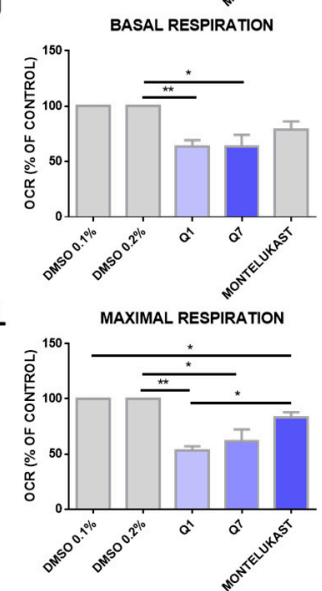

Figure 9. Quininib analogues inhibit oxidative phosphorylation, but not glycolysis, following $24 \mathrm{~h}$ treatment in Mel285 and OMM2.5 cell lines. Analysis of cellular metabolism in Mel285 (A-F) and OMM2.5 (G-L) UM cell lines. Oxygen consumption rate (OCR), a measure of oxidative phosphorylation, was evaluated in Mel285 $(n=5)(\mathrm{A})$ and OMM2.5 $(n=4)(\mathbf{G})$ cells using the Seahorse Biosciences XFe24 analyser following $24 \mathrm{~h}$ treatment with $20 \mu \mathrm{M}$ of test compound or DMSO control. (A) $20 \mu \mathrm{M}$ quininib (Q1) and $20 \mu \mathrm{M}$ 1,4-dihydroxy quininib (Q7) significantly reduced OCR in Mel285 cells versus DMSO control. (G) $20 \mu \mathrm{M}$ quininib, 1,4-dihydroxy quininib, and montelukast significantly reduced OCR in OMM2.5 cells versus DMSO control. Extracellular acidification rate (ECAR), a measure of glycolysis was evaluated in Mel285 (B) and OMM2.5 cells (H) following $24 \mathrm{~h}$ treatment. OCR:ECAR ratio was measured in Mel285 (C) and OMM2.5 (I) cells following $24 \mathrm{~h}$ treatment. Basal respiration was significantly reduced in Mel285 (D) and OMM2.5 (J) cells following $24 \mathrm{~h}$ treatment with quininib analogues at $20 \mu \mathrm{M}$. (E) ATP production was significantly reduced in Mel285 cells following $24 \mathrm{~h}$ treatment with quininib. (K) ATP production was significantly decreased in OMM2.5 cells following $24 \mathrm{~h}$ treatment with quininib and 1,4-dihydroxy quininib. (F) Maximal respiration was significantly reduced in Mel285 cells following $24 \mathrm{~h}$ treatment with quininib. (L) Maximal respiration was significantly reduced in OMM2.5 following $24 \mathrm{~h}$ treatment with quininib, 1,4-dihydroxy quininib, and montelukast. Data are expressed as mean + SEM. Statistical analysis was carried out using a paired $t$-test to compare within the same cell line. Data was normalised to cell number, as assessed by crystal violet assay. ${ }^{*} p<0.05 ;{ }^{* *} p<0.01 ;{ }^{* * *} p<0.001$.

\subsection{CysLT 1 Antagonists Inhibit the In Vivo Growth of Uveal Melanoma Zebrafish Xenografts}

To determine if the in vitro attenuation of UM cell proliferation with $\mathrm{CysLT}_{1}$ antagonists could be reproduced in vivo, we sought to generate mouse and zebrafish UM cell xenografts [49]. In our experience, Mel285 cell lines were not amenable to generate murine xenograft models following subcutaneous, intraocular, intrahepatic, or intravenous implantation. In contrast, the metastatic OMM2.5 cell line produced tumours following subcutaneous, intraocular, or intrahepatic implantation. However, this required lengthy growth times of 7-8 months for the initial subcutaneous cell suspension injection, and 3-4 months for propagation from corresponding subcutaneous fragment implants (Figure S5). OMM2.5 cells implanted intraocularly give rise to ocular tumours 3-4 months post cell suspension injection (Figure S5A,B). Similarly, OMM2.5 cells implanted intrahepatically allow 
tumour growth 3-4 months after cell suspension injection (Figure S5C,D), and 1-2 months after the re-implantation of tumour fragments arising (Figure S5E). Histological examination of the tumours confirmed the presence of a UM cell phenotype (Figure S5F-H). Further characterisation of these murine UM xenografts models will ascertain their value in researching the therapeutic effect of UM treatments.

The zebrafish xenograft models proved to be more time- and cost-effective and thus allowed investigation of the effects of the CysLT 1 antagonists on UM cell lines in vivo. Mel285 and OMM2.5 UM cell lines were injected into the perivitelline space or eye of $2 \mathrm{dpf}$ (days post-fertilisation) zebrafish larvae. Following injection, the larvae were treated with the maximum tolerated dose of quininib (3 $\mu \mathrm{M}), 1$,4-dihyroxy quininib $(10 \mu \mathrm{M})$ or montelukast $(20 \mu \mathrm{M})$. Montelukast significantly reduced the tumour size of Mel285 xenografts propagated in the perivitelline space ( $p=0.0498,14.6 \%$ reduction) or eye ( $p<0.0001,32.4 \%$ reduction) (Figure 10A). In contrast, montelukast had negligible effect on OMM2.5 xenografts in the perivitelline space but modestly reduced ( $p=0.0439$ and 25.6\% reduction) tumour size in the eye (Figure 10B). In relation to quininib and 1,4-dihydroxy quininib, the most significant reductions in tumour size were also observed with the Mel285 cells line xenografts in the eye ( $p<0.0001$ and $26.2 \%$ reduction versus $p<0.0001$ and $21.7 \%$ reduction, respectively) (Figure 10A). Quininib and 1,4-dihydroxy quininib had negligible effects on OMM2.5 xenografts into the perivitelline space, whereas 1,4-dihydroxy quininib modestly reduced ( $p=0.0258$ and $18.4 \%$ reduction) OMM2.5 xenograft growth in the eye (Figure 10B). In summary, CysLT 1 antagonists can inhibit the in vivo growth of UM cancer cells; however, the effects are more pronounced with the primary Mel285 compared to the metastatic OMM2.5 cell line. Similarly, the drugs seem to have a more pronounced effect on cells implanted into the eye, the physiologically relevant organ, rather than those implanted into the perivitelline space.

A

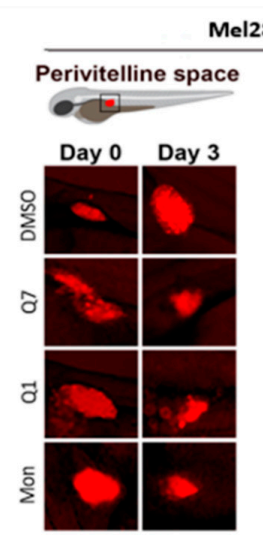

Mel285 PVS

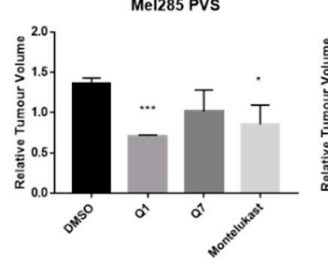

Mel285

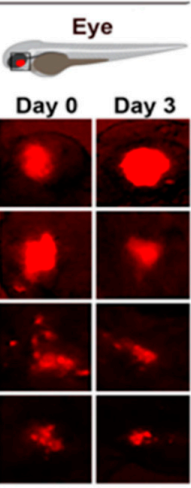

Mel285 Eye

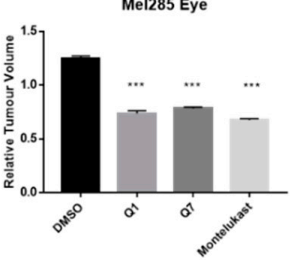

B

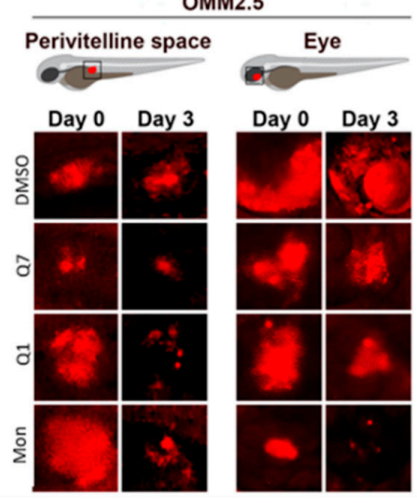

OMM2.5 PVS

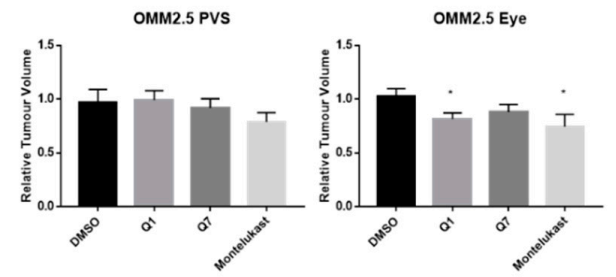

Figure 10. CysLT 1 antagonists inhibit the growth of $\mathrm{UM}$ cell lines in in vivo zebrafish xenograft models. Zebrafish cell line-derived xenograft models were developed using Mel285 and OMM2.5 cell lines. Labelled UM cells were implanted into the perivitelline space (PVS) or vitreous of $48 \mathrm{hpf}$ (hours post-fetilisation) $\mathrm{Tg}(f l i 1 a: E G F P)^{\mathrm{y} 1}$ zebrafish embryos and treated with the maximum tolerated dose of test compound, or DMSO control. (A) Treatment with $3 \mu \mathrm{M}$ quininib (Q1), $10 \mu \mathrm{M}$ 1,4-dihydroxy quininib (Q7) and $20 \mu \mathrm{M}$ montelukast (Mon) significantly reduced the growth of Mel285 xenografts in the zebrafish eye $(p<0.0001)$. (B) Treatment with $10 \mu \mathrm{M}$ 1,4-dihydroxy quininib and $20 \mu \mathrm{M}$ montelukast significantly reduced the growth of OMM2.5 xenografts in the zebrafish eye ( $p=0.0258$ and $p=0.0439$, respectively). Relative change in tumour volume was evaluated as the size of the tumours at three days post implantation ( $3 \mathrm{dpi} / 5 \mathrm{dpf})$ relative to the size immediately after implantation (at $0 \mathrm{dpi} / 2 \mathrm{dpf}$ ). 


\section{Discussion}

We identified that high CysLT 1 expression is associated with survival of primary UM patients and that antagonism of $\mathrm{CysLT}_{1}$ alters cancer hallmarks in UM cells in vitro and in vivo.

To our knowledge, this is the first study to investigate the link between the expression of CysLT receptors in UM patient samples and associated clinical data. Gene expression data from TCGA suggest that high expression of CYSLTR1 or CYSLTR2 is significantly linked to disease-free and overall survival in UM patients. This is supported by the known importance of the $C y s L T_{2} / G_{\alpha q / 11} / P L C B 4$ pathway in UM oncogenesis. CYSLTR2 acts as an oncogene [12], albeit in a small subset of UM. Activation of this receptor, and the associated downstream signalling pathways, are identified drivers of disease progression in early UM [50].

TCGA data suggest that high expression of CYSLTR1 is associated with a poor patient prognosis in UM. This finding was supported by the data generated at the protein level using the patient UM TMA, whereby CysLT $_{1}$ was significantly associated with reduced melanoma-specific survival and reduced overall survival in a primary $\mathrm{UM}$ patient cohort. CysLT 1 was highly expressed in primary $\mathrm{UM}$, with 52/52 tissue samples staining positive for the receptor.

$\mathrm{CysLT}_{2}$ was highly expressed in all primary UM examined, with 51/51 tissue samples staining positive for the receptor. All patient samples stained were positive for both $\mathrm{CysLT}_{1}$ and $\mathrm{CysLT}_{2}$. Both receptors are not highly expressed in normal uveal tract [51], which suggests a role in early carcinogenesis. Of note, high CysLT 1 expression is associated with poor prognosis and reduced survival in both colorectal [28] and breast cancer [29], while CysLT 2 has been reported to have an anti-tumorigenic effect in colorectal cancer [52].

Interestingly, high expression of $\mathrm{CysLT}_{1}$ was also significantly associated with ciliary body involvement, a feature associated with an increased risk of metastasis [53]. This further suggests a potential link between CysLT $_{1}$ expression and patient prognosis. Given their link to the MAPK pathway, and the known importance of this pathway in UM, it is not surprising that CysLT receptors are highly expressed in primary UM. Similarly, based on the biology of CysLT receptors it is unsurprising that high expression of both $\mathrm{CysLT}_{1}$ and $\mathrm{CysLT}_{2}$ in $\mathrm{UM}$ are associated with significant alterations in inflammation and angiogenesis. Indeed, their high level of expression and link to prognostic and clinical features of the disease may suggest that they are associated with malignant transformation of the tumour. Thus, further investigation using additional UM patient samples is warranted to determine if high $\mathrm{CysLT}_{1}$ or $\mathrm{CysLT}_{2}$ expression can be statistically associated with patient prognosis and metastatic disease development.

As CysLT receptors are druggable G-protein coupled receptors, we hypothesised that pharmacological antagonists of these receptors may attenuate cancer phenotypes of UM cells in culture. qPCR and western blot analysis confirmed equivalent expression of both receptors in Mel285 and OMM2.5 cell lines suggesting that phenotypic differences observed following drug treatment are not due to differences in CysLT receptor expression. The CysLT 2 antagonist HAMI 3379 was previously tested in Leu129Gln CysLT 2 UM oncogene models but showed limited activity as an inverse agonist in these models of constitutive $\mathrm{CysLT}_{2}$ activation [54]. To our knowledge, no previous studies have investigated the anti-cancer potential of $\mathrm{CysLT}_{1}$ antagonists in $\mathrm{UM}$. However, montelukast exerts anti-cancer activity in chronic myeloid leukaemia [55], colorectal cancer [56], lung cancer [57], and is chemopreventative against 14 different cancer types [23]. Likewise, quininib and 1,4 dihydroxy quininib have significant anti-cancer properties in colorectal cancer models [34,35]. Here, we uncover that $\mathrm{CysLT}_{1}$ antagonists, but not $\mathrm{CysLT}_{2}$ antagonists, produce significant anti-cancer effect in primary and metastatic UM cell lines through the inhibition of cell survival and cell proliferation.96 hours of drug treatment in short-term cell viability and long-term cell proliferation assays revealed interesting results. The CysLT 2 antagonist HAMI 3379 had no effect on the viability of the primary or metastatic $\mathrm{UM}$ cell lines. All three $\mathrm{CysLT}_{1}$ antagonists significantly reduced viability of the primary and metastatic UM cells, with no intra-drug differences across the cell lines, but with quininib being the most potent in both cell lines. Dacarbazine, a chemotherapeutic clinically used in treatment of metastatic UM, did not 
reduce the viability of either UM cell line. This is consistent with clinical findings wherein dacarbazine did not offer any survival advantage in treating metastatic disease [6] or in the adjuvant setting after primary tumour resection [58]. Of note, here, all $\mathrm{CysLT}_{1}$ drugs tested performed significantly better than dacarbazine. In long-term proliferation assays, the $\mathrm{CysLT}_{2}$ antagonist HAMI 3379 again exerted negligible effect on the primary or metastatic UM cell lines. The CysLT 1 antagonists quininib and 1,4-dihydroxy quininib significantly attenuated proliferation of both cell lines with a seemingly higher efficacy in the primary UM cell line. The same effects of $\mathrm{CysLT}_{1}$ antagonists are not observed in ARPE-19 cells, suggesting that this is a specific effect in UM cells.

Here, we identify quininib and 1,4-dihydroxy quininib to significantly alter the secretion of cancer-associated inflammatory and angiogenic factors from UM cell lines. In agreement, the anti-angiogenic and anti- inflammatory actions of $\mathrm{CysLT}_{1}$ antagonists are known in other contexts $[32,33,59]$. CysLTs modulate vascular permeability through upregulation of VEGF expression [60] and $\mathrm{CysLT}_{1}$ antagonists modulate vascular permeability through reduction of VEGF expression in mice [61] and in human asthmatic patients [62]. Likewise, the eyes of UM patients often contain increased levels of inflammation-related cytokines in the aqueous humour [63] and several in vitro studies show the expression of soluble inflammatory factors in UM. Our TCGA data analysis also suggests that high expression of CysLT receptors is significantly linked to pro-inflammatory and pro-angiogenic pathways. In relation to secreted inflammatory and angiogenic factors, again montelukast and HAMI 3379 had negligible effects. It has been reported that blocking pro-angiogenic isoforms of VEGF, through inhibition of SRPK1, inhibits melanoma tumour growth in vivo [64]. Quininib and 1,4-dihydroxy resulted in significant, but dramatically differential effects on the cell lines and factors. For example, quininib treatment was associated with a significant increase in VEGF-C secretion from Mel285 cells, but not from OMM2.5 cells. 1,4-dihydroxy quininib had negligible effects on VEGF-C secretion, but significantly increased Flt-1 in Mel285 in contrast to quininib which had no effect. Interestingly, Flt-1 negatively modulates angiogenesis via its actions as a decoy receptor by trapping VEGF and preventing its binding to VEGFR-2 [65]. Further investigation is required to determine if the drug-induced changes in angiogenic factor expression are cause-or-effect for the corresponding reduction in UM cell viability and proliferation.

Profound differences in the secretion of inflammatory markers was also observed with the quininib drugs. For example, quininib significantly reduced the secretion of IL-2 in Mel285 cells, but significantly increased IL-2 secretion from OMM2.5 cells, whereas 1,4 -dihydroxy quininib exerted negligible effects on IL-2 in OMM2.5 cells. Particularly noticeable is the significantly increased secretion of seven inflammatory factors in OMM2.5, but not Mel285, after quininib, but not 1,4-dihydroxy quininib, treatment. Notably, $24 \mathrm{~h}$ treatment with quininib reduced the survival and proliferation of Mel285 but not OMM2.5 cells. This is potentially due to a resistance associated up-regulation of inflammatory factors in OMM2.5 cells. Indeed, the basal expression of IL-13 and IL-8 is much higher in OMM2.5 than Mel285 cells. The pattern of IL-2 and IL-6 secretion may explain the similar actions of quininib drugs on proliferation in the Mel285 cells. UM cell lines express IL-2R, and production of the IL-2 ligand by tumour infiltrating lymphocytes and macrophages stimulates tumour cell proliferation [66]. IL-6 stimulates tumour cell proliferation and survival through the inhibition of apoptosis and interference with IL-6R signalling leads to decreased UM cell viability [67]. Quininib and 1,4 dihydroxy quininib result in 3-5-fold reductions in secreted levels of IL-2 and IL-6. Changes in IL-2 and IL-6 are not sufficient to explain effects on the OMM2.5 cells, but anti-proliferative effects in these cells may be confounded by the up-regulation of multiple other inflammatory factors.

The importance of dysregulated metabolism in the initiation and progression of cancer is well understood. Although much is known about metabolic rewiring in cutaneous melanoma, few studies focus solely on the metabolic underpinnings of UM. Oxidative phosphorylation is upregulated in invasive melanoma [68] and the metabolic switch of some melanomas to oxidative phosphorylation has been linked to resistance to inhibitors of the MAPK pathway [69]. While CysLT are predominantly known for their role in inflammation and angiogenesis, they are linked to alterations in respiratory 
activity. $\mathrm{LTD}_{4}$ increases mitochondrial metabolic activity and mitochondrial gene transcription in human intestinal epithelial cells and colorectal cancer cells [70]. Significantly decreased oxidative phosphorylation was observed in Mel285 and OMM2.5 cells with quininib or 1,4-dihydroxy quininib and OMM2.5 cells with montelukast. Modulation of oxidative phosphorylation controls proliferation of tumour cells [71] which may explain the effect of $\mathrm{CysLT}_{1}$ antagonists on UM cells.

In vivo models are preferable to human cell lines to study the complexity of the tumour microenvironment. Zebrafish xenograft models have been established as robust preclinical models in which experimental drugs can be tested [49]. To this end, we created xenograft models using UM cell lines, to determine if the effects of $\mathrm{CysLT}_{1}$ antagonists on UM cell survival and proliferation can be recapitulated in a more complex system. Our in vitro data are supported by the results generated in zebrafish models whereby CysLT 1 antagonist drugs significantly inhibit the growth of both Mel285 and OMM2.5 zebrafish xenograft models. Interestingly, $\mathrm{CysLT}_{1}$ antagonists have a greater effect in zebrafish orthoxenograft models, in which the cells are implanted into the corresponding anatomical location. Given that the Mel285 cell line originated in the eye, and the OMM2.5 cell line originated in the liver, this may explain the more substantial effect observed in the Mel285 orthoxenograft model. To further validate our results, we have generated an OMM2.5 cell line-derived orthotopic xenograft mouse model of UM. This and patient-derived UM xenografts are considered the most appropriate pre-clinical models for future studies to evaluate the potential of $\mathrm{CysLT}_{1}$ antagonist as therapeutics for UM.

\section{Materials and Methods}

\subsection{Cell Culture}

UM cell lines derived from primary (Mel285, Mel270) and metastatic (OMM2.5) UM were kindly provided by Dr. Martine Jager (Leiden, The Netherlands) [41]. Cell lines were maintained at $37^{\circ} \mathrm{C} / 5 \%$ $\mathrm{CO}_{2}$ in RPMI 1640 Medium (Gibco, Gaithersburg, MD, USA) supplemented with 10\% FBS and 2\% Penicillin/Streptomycin. ARPE-19 cells were maintained at $37^{\circ} \mathrm{C} / 5 \% \mathrm{CO}_{2}$ in DMEM: F12 (Lonza, Basel, Switzerland) supplemented with 10\% FBS, 1\% Penicillin/Streptomycin and $2.5 \mathrm{mM}$ L-Glutamine.

\subsection{Drug Preparation}

Quininib (Q1), 1,4-dihydroxy quininib (Q7) [32,33], montelukast (Mon) (Sigma-Aldrich, St. Louis, MO, USA \#SML0101), HAMI 3379 (Cayman Chemical, Ann Arbor, MI, USA \#10580) and dacarbazine (Sigma-Aldrich, St. Louis, MO, USA \#D2390) were dissolved in 100\% DMSO and stored as (10-50 mM) stock solutions. Working solutions $(100 \mu \mathrm{M})$ were prepared fresh prior to each experiment in complete cell culture medium as described above. Drugs were made to final test concentrations by adding the required volume of the working solution to cells in complete media. $0.1 \%$ and $0.2 \%$ DMSO were used as controls in Seahorse Assay experiments.0.5\% DMSO was used as a control for all other drug treatment experiments.

\subsection{MTT Assay}

3-(4,5-dimethylthiazol-2-yl)-2,5-diphenyltetrazolium bromide) dye determined cytotoxic effects in cell lines. Cells were trypsinised using trypsin-EDTA (0.05\%) (ThermoFisher Scientific, Rockford, IL, USA) and centrifuged at $1200 \mathrm{rpm}$ for $5 \mathrm{~min}$ at RT. Cell pellets were re-suspended in complete medium and cells seeded into 96-well plates at 5000 cells/well. After $24 \mathrm{~h}$ adherence, cell medium was removed and replaced with the desired drug concentration. 0.5\% DMSO in RPMI 1640 (UM cells) or DMEM (ARPE-19 cells) was used as a vehicle control. Cells were incubated for 24 and $96 \mathrm{~h}$ with drugs. Drug solution was removed, and the wells washed with PBS before adding $90 \mu \mathrm{L}$ of serum-free medium and $10 \mu \mathrm{L}$ MTT (3-(4,5-dimethylthiazol-2-yl)-2,5-diphenyltetrazolium bromide) dye to each well. The plate was covered and incubated for $2.5 \mathrm{~h}$ at $37^{\circ} \mathrm{C}$. Then, $100 \mu \mathrm{L}$ of $100 \%$ DMSO was added to each well to 
dissolve the formazan crystals. Absorbance values at $570 \mathrm{~nm}$ were determined using a SpectraMax ${ }^{\circledR}$ M2 microplate reader (Molecular Devices Corporation, Sunnyvale, CA, USA).

\subsection{Colony Formation Assay}

$1.5 \times 10^{3}(\mathrm{Mel285})$ or $9 \times 10^{3}(\mathrm{OMM} 2.5)$ cells were seeded per well of a 6-well plate and allowed adhere for $24 \mathrm{~h}$. Cells were treated with the desired concentration of drug for 24 or $96 \mathrm{~h} .0 .5 \%$ DMSO was used as a vehicle control. Following treatment, the drug solution was removed, and cells grown in complete medium for 10 days. Clones were fixed with $4 \%$ paraformaldehyde for $10 \mathrm{~min}$ and stained using $0.5 \%$ crystal violet (Pro-Lab diagnostics, Wirral, UK \#PL700) for $2 \mathrm{~h}$ at RT. Clone counting was performed using the GelCount ${ }^{\mathrm{TM}}$ system (Oxford Optronix, Abingdon, UK).

\subsection{Statistical Analysis for Drug Treatment Experiments}

Statistical analysis applied GraphPad Prism 7 software (GraphPad, San Diego, CA, USA). Specific statistical tests used are indicated in figure legends. All data are presented as mean \pm standard error of the mean (SEM). For all statistical analysis, differences were considered statistically significant at $p<0.05$. For MTT assay drug treatments, statistical analysis was performed by ANOVA with Dunnett's post hoc multiple comparison test. Error bars are mean + S.E. ${ }^{*} p<0.05 ;{ }^{* *} p<0.01 ;{ }^{* * *} p<0.001$; ${ }_{* * * *} p<0.0001$. For clonogenic assay drug treatments, statistical analysis was performed by ANOVA with Dunnett's post hoc multiple comparison test. Error bars are mean + S.E. ${ }^{*} p<0.05$; ${ }^{* * *} p<0.001$; $* * * * *<<0.0001$

\section{6. $\mathrm{CysLT}_{1}$ and $\mathrm{CysLT}_{2} q P C R$}

Total RNA was extracted from UM cells using the mirVana ${ }^{\mathrm{TM}}$ miRNA Isolation Kit (ThermoFisher Scientific, Rockford, IL, USA) as per the manufacturer's instructions. Briefly, cells were trypsinised and washed by gently resuspending in $1 \mathrm{~mL}$ of PBS and pelleting at $1200 \mathrm{rpm}$ prior to lysis and total RNA isolation. Following isolation, total RNA concentration was quantified at $260 \mathrm{~nm}$ (Spectrophotometer ND-2000, Thermo Scientific, Wilmington, DE, USA) and samples stored at $-80^{\circ} \mathrm{C}$. cDNA was synthesized with the SuperScript II Reverse Transcriptase system (Invitrogen, Carlsbad, CA, USA) or the TaKaRa PrimeScript ${ }^{\mathrm{TM}}$ RT Reagent Kit (Takara Bio Europe, Saint-Germain-en-Laye, France), using random hexamers as per the supplier's instructions.

\subsection{CysLT 1 and CysLT 2 Western Blot}

UM cells were seeded at $2.5 \times 10^{5}$ cells per well of a 6-well plate and left adhere for $24 \mathrm{~h}$. Total protein was extracted from cells. Cells were washed in ice-cold PBS and lysed with RIPA buffer (Sigma-Aldrich, St. Louis, MO, USA) supplemented with $200 \mathrm{mM} \mathrm{NaF}, 100 \mathrm{mM}$ PMSF, $100 \mathrm{mM}$ sodium orthovanadate, 1X protease inhibitor cocktail (Sigma-Aldrich, St. Louis, MO, USA), 1X phosphatase inhibitor cocktail 2 (Sigma-Aldrich, St. Louis, MO, USA) and 1X phosphatase inhibitor cocktail 3 (Sigma-Aldrich, St. Louis, MO, USA). Following lysis, cells were scraped into an Eppendorf and left on ice for $45 \mathrm{~min}$, with vortexing at 15 -min intervals. Cells were centrifuged at 14,000 rpm for $30 \mathrm{~min}$ at $4{ }^{\circ} \mathrm{C}$. After centrifugation, the supernatant was collected and stored at $-80{ }^{\circ} \mathrm{C}$. Protein concentrations were determined using the BCA protein assay kit (ThermoFisher Scientific, Rockford, IL, USA). Then, $15 \mu \mathrm{g}$ of protein were prepared in $4 \mathrm{X}$ sample buffer and 10X reducing agent and separated by $10 \%$ SDS/PAGE, transferred to PVDF membranes (MilliporeSigma, Burlington, MA, USA), and probed with primary antibodies (CysLT 1 : Abcam, Cambridge, UK [ab151484], 1:1000, CysLT 2 : Cayman Chemical, Ann Arbor, MI, USA [CAY120560] 1:1000, Alpha-Tubulin: Santa Cruz, Dallas, TX, USA, 1:1000). Secondary antibodies were anti-mouse IgG HRP-linked (Cell Signalling, Danvers, MA, USA [7076S] 1:1000), or anti-rabbit IgG HRP-linked (Cell Signalling, Danvers, MA, USA [7074S] 1:1000). Signal was detected using enhanced chemiluminescence as per the manufacturer's instructions (Pierce ${ }^{\mathrm{TM}}$ ECL Western Blotting Substrate, ThermoFisher Scientific, Rockford, IL, USA). 


\subsection{The Cancer Genome Atlas Gene Expression Analysis}

Gene expression and clinical data from 80 primary UM included in The Cancer Genome Atlas (TCGA-UM dataset) were collected from the GDC data portal through the R package "TCGAbiolinks". RNA-seq data were downloaded in Fragments Per Kilobase of exon per million fragments Mapped (FPKM) and then converted to log2 scale. The associations between CYSLTR1 and CYSLTR2 gene expression and prognosis were assessed by Cox proportional hazard regression models, adjusted by sex and age (Table S1). To resolve a violation of the proportional hazard assumption, the association between CYSLTR2 gene expression and overall survival (Figure 1E) was stratified by time from 0-20 months and beyond 20 months and analysed by the likelihood ratio (LHR) test (Table S1). Disease-Free Survival (DFS) and Overall Survival (OS) were used as end points. The third quartile was used as an optimal cut-off to divide samples into High and Low expression categories. Survival probabilities were plotted on a Kaplan-Meier curve and a Log-rank test was used to compare the two groups. Survival analysis was performed with $R$ package "survminer". Disease-free survival is defined as time to metastatic recurrence. Overall survival is defined as death by any cause.

Gene Set Variation Analysis was performed to calculate enrichment scores in functions and pathways "Inflammatory response", "INF- $\gamma$ ", "Glycolysis", “Oxidative Phosphorylation", "TNF- $\alpha$ ”, "Angiogenesis", and "GPCR signalling" (R package "GSVA"). They were manually selected from the Molecular Signatures Database (MSigDB) which includes gene sets from Hallmarks and Biocarta-curated pathways. Samples were divided by the third quartile gene expression values of CYSLTR1 and CYSLTR2. For each score obtained, differences were assessed using a non-parametric Wilcoxon test. Differences were considered statistically significant when $p$-value $<0.05$.

To infer contributions from stromal infiltration, MCP-counter and ESTIMATE tools were used [72]. MCP-counter (Microenvironment Cell Populations-counter) uses gene expression profiles to quantify the relative abundance of a series of immune and non-immune cell types ( $T$ cells, cytotoxic $T$ cells, NK cells, B lineage, monocytic lineage, dendritic cells, neutrophils, endothelial cells, and cancer associated fibroblasts). Estimation of STromal and Immune cells in MAlignant Tumor tissues using Expression data (ESTIMATE) is a tool that infers tumour purity and stromal/immune infiltration using gene expression data. Spearman correlation tests were performed to assess correlation between CYSLTR1 and CYSLTR2 gene expression and the corresponding MCP-counter scores. Stromal scores from ESTIMATE were used to adjust CYSLTR1 and CYSLTR2 expression values and recalculate the survival models (Figure S1).

\subsection{Ethics}

This study conformed to the principles of the Declaration of Helsinki and Good Clinical Practice guidelines. Approval for the study was obtained from the Health Research Authority (NRES REC ref 16/NW/0380) on the 16th of May 2016, and all patients provided informed consent.

All experiments involving the use of rodents were approved by the Ethical Committee of Animal Experimentation of the Parc Científic de Barcelona (PCB) under the procedure number 9928-P1 approved by the Generalitat de Catalunya.

\subsection{Tissue Samples}

A tissue microarray (TMA) was generated from primary UM samples of 52 consented patients treated at the Liverpool Ocular Oncology Centre, with the primary UM samples being stored within the Liverpool Ocular Oncology Biobank (HTA Licence 12020 and HRA REC 16/NW/0380).

\subsection{Immunohistochemistry}

IHC for CysLT 1 (Abcam, Cambridge, UK [ab151484], 1:200) and CysLT 2 (Cayman Chemical, Ann Arbor, MI, USA [CAY120560], 1:500) was performed on 4- $\mu \mathrm{m}$ FFPE sections arranged on the above mentioned TMA using commercial equipment (Leica Bond RXm System; Leica Microsystems Ltd., 
Milton Keynes, UK) and a detection kit (Bond Polymer Refine Red Detection Kit; Leica Biosystems, Inc., Buffalo Grove, IL, USA) as previously described [73]. Slides were counterstained with hematoxylin and mounted using DPX mountant (Sigma-Aldrich, St. Louis, MO, USA). Colorectal cancer tissue served as the positive control (Figure S2A); negative control was omission of the primary antibody (Figure S2A). Slides were scanned using a slide scanner (Aperio CS2; Leica Biosystems, Inc., Buffalo Grove, IL, USA) and analysed with imaging software (Aperio Image Scope version 11.2; Leica Biosystems, Inc., Buffalo Grove, IL, USA). Each core was scored based on intensity $(0,1,2$, or 3$)$ and percentage of tumour cells stained. The final score was calculated using the following equation: (scoring intensity $\times \%$ of cells stained)/n number of samples [73]. The IHC-stained slides were scored by three independent investigators (S.E.C., H.K., K.S.). Melanoma-specific survival is defined as death from metastatic melanoma. Overall survival is defined as death by any cause.

\subsection{Digital Slide Scanning and Automated Image Analysis}

Slides were scanned with an Aperio AT2 digital slide scanner (Leica Biosystem, Milton Keynes, UK) with a $20 \times$ lens, and the quality of the images was checked manually before the application of the digital algorithm. Automated digital image analysis was performed using the Visiopharm Integrator System (Visiopharm, Hoersholm, Denmark). A cytoplasmic algorithm from the ONCOTOPIX module (v4.2.2.0, Visiopharm, Hoersholm, Denmark) was fine-tuned for the interpretation of CysLT 1 and $\mathrm{CysLT}_{2}$ staining. $\mathrm{H}$-score was used as the image analysis output, which was calculated using the following formula: $[1 \times(\%$ of weakly positive cells $)+2 \times(\%$ of moderately strong positive cells $)+3 \times$ (\% strong positive cells)], where the $\mathrm{H}$-score of 0-100 was generally categorized as low expression, 101-200 as intermediate expression, and 201-300 as high expression of $\mathrm{CysLT}_{1}$ and $\mathrm{CysLT}_{2}$ (Figure 3A).

\subsection{Statistical Analysis for Immunohistochemistry}

Bivariate analysis of high expression of $\mathrm{CysLT}_{1} / \mathrm{CysLT}_{2}$ associated with melanoma-specific survival or overall survival was undertaken using the Cox proportional hazards model. Survival time (years) was calculated from the date of first diagnosis until death, or study closure on 29 May 2019. All analyses were carried out using SPSS Statistics v.24 (IBM, Armonk, NY, USA).

\subsection{Mel285 and OMM2.5 ELISA}

Cells were seeded at $1.5 \times 10^{5}$ cells per well of a 6-well plate and allowed adhere overnight. Cells were treated with $20 \mu \mathrm{M}$ of quininib, 1-4-dihydroxy quininib, montelukast, HAMI 3379, or $0.5 \%$ DMSO as control. All treatments were conducted in duplicate. Following $24 \mathrm{~h}$ treatment, $1 \mathrm{~mL}$ of media was removed from each well and stored at $-20^{\circ} \mathrm{C}$. Media were processed according to the Meso Scale Discovery (MSD) multiplex protocol. To assess angiogenic and inflammatory secretions from cell conditioned media, a 17-plex ELISA kit separated across three plates was used (Meso Scale Diagnostics, Rockville, MD, USA). The multiplex ELISA determined the secreted levels of; IFN- $\gamma$, IL-10, IL-12p70, IL-13, IL-1 $\beta$, IL-2, IL-4, IL-6, IL-8, TNF- $\alpha$, bFGF, Flt-1, PIGF, Tie-2, VEGF-C, VEGF-D, and VEGF-A in cell conditioned media. Assays were run as per the manufacturer's recommendation; an overnight supernatant incubation protocol was used for the Pro-inflammatory Panel 1 with the Angiogenesis Panel 1 assay being run on the same day protocol. Cell-conditioned media were run undiluted on all assays as per previous optimisation experiments. Secretion data for all factors were normalised to cell lysate protein content (extracted as described above) by using a BCA protein assay kit (ThermoFisher Scientific, Rockford, IL, USA).

\subsection{Zebrafish Breeding and Maintenance}

All experiments carried out on animals were granted ethical approval by Linköping Experimental Animal Research Ethics Committee under the ethical approval number N89/15. Zebrafish were maintained in a 14-h light, 10-h dark cycle in a recirculating water system at $28{ }^{\circ} \mathrm{C}$. Larvae were produced through natural spawning and maintained as previously described [74]. 


\subsection{Zebrafish Cell Line Xenografts}

Implantation of Mel285 or OMM2.5 cells into zebrafish embryos followed published protocols [75]. Briefly, cells were labelled for $30 \mathrm{~min}$ at $37^{\circ} \mathrm{C}$ in $6 \mathrm{mg} / \mathrm{mL}$ DiI (Sigma-Aldrich, St. Louis, MO, USA) in PBS followed by washing $3 \times$ in PBS. Labelled cells were implanted in the perivitelline space or vitreous of $48 \mathrm{hpf}$ (hours post-fertilisation) $\mathrm{Tg}(f l i 1 a: E G F P)^{y 1}$ zebrafish embryos, maintained from the 8-cell stage in $0.003 \%$ PTU-containing E3-water $(5 \mathrm{mM} \mathrm{NaCl}, 0.17 \mathrm{mM} \mathrm{KCl}, 0.33 \mathrm{mM} \mathrm{CaCl}, 0.33 \mathrm{mM}$ $\mathrm{MgSO}_{4}$ ). Approximately, $200-500$ cells in $2-5 \mathrm{~nL}$ were implanted in each embryo ( 20 embryos per group). Embryos were transferred to individual wells of 24 -well plates containing $0.5 \mathrm{~mL}$ quininib, 1-4-dihydroxy quininib or montelukast at $10 \mathrm{mM}$ final concentration in E3-PTU water. Tumour-bearing embryos were imaged using a fluorescent microscope (SMZ1500, Nikon, Tokyo, Japan) soon after implantation. Embryos with tumour cells erroneously implanted in the yolk, brain, or circulation were removed. Embryos bearing tumours in the perivitelline space or the vitreous were incubated at $36{ }^{\circ} \mathrm{C}$ for three days and re-imaged. Relative change in tumour volume was evaluated as the size of the tumours at three days post-implantation ( $3 \mathrm{dpi}$ ) relative to the size immediately after implantation (at 0 dpi).

\subsection{Seahorse Metabolism Measurements}

Mel285 and OMM2.5 were seeded in four wells per treatment group at a density of $12 \times 10^{3}$ and $14 \times 10^{3}$ cells per well, respectively, in a 24-well cell culture XFe24 microplate (Agilent Technologies, Santa Clara, CA, USA) at a volume of $100 \mu \mathrm{L}$ RPMI and allowed to adhere at $37^{\circ} \mathrm{C}$ and $5 \% \mathrm{CO}_{2}$ for $5 \mathrm{~h}$; then an additional $150 \mu \mathrm{L}$ of RPMI was added. Twenty-four hours following seeding, cells were treated with $20 \mu \mathrm{M}$ of quininib, 1-4-dihydroxy quininib or montelukast along with $0.1 \%$ and $0.2 \%$ DMSO controls. Twenty-four hours following drug treatment, cells were washed with unbuffered DMEM supplemented with $10 \mathrm{mM}$ glucose, $10 \mathrm{mM}$ sodium pyruvate ( $\mathrm{pH}$ 7.4), and incubated for $1 \mathrm{~h}$ at $37^{\circ} \mathrm{C}$ in a $\mathrm{CO}_{2}$-free incubator. The oxygen consumption rate (OCR) and extracellular acidification rate (ECAR) were measured using a Seahorse Biosciences XFe24 Extracellular Flux Analyser (Agilent Technologies, Santa Clara, CA, USA). Three basal measurements of OCR and ECAR were taken over 24 min consisting of three repeats of mix (three $\mathrm{min}$ )/wait (2 $\mathrm{min})$ /measurement ( $3 \mathrm{~min}$ ) to establish OCR measurement. Three additional measurements were obtained following the injection of three mitochondrial inhibitors including oligomycin $(2 \mu \mathrm{g} / \mathrm{mL}$ ) (Sigma-Aldrich, St. Louis, MO, USA), an uncoupling agent carbonyl cyanide 4-(trifluoromethoxy) phenylhydrazone (FCCP) $(5 \mu \mathrm{M})$ (Sigma-Aldrich, St. Louis, MO, USA), and antimycin-A $(2 \mu \mathrm{M})$ (Sigma-Aldrich, St. Louis, MO, USA), and ATP turnover was calculated by subtracting the OCR post oligomycin injection from baseline OCR prior to oligomycin addition. Proton leak was calculated by subtracting OCR post antimycin-A addition from OCR post oligomycin addition. Maximal respiration was calculated by subtracting OCR post antimycin addition from OCR post FCCP addition. Non-mitochondrial respiration was determined as the OCR value post antimycin-A addition. All measurements were normalised to cell number using the crystal violet assay, transferring the eluted stain to a 96-well plate before reading.

\subsection{Crystal Violet Assay}

Cells were fixed in a $1 \%$ glutaraldehyde solution for $15 \mathrm{~min}$ at room temperature followed by two washes in $100 \mu \mathrm{L}$ of PBS. Cells were stained with $0.1 \%$ crystal violet for $30 \mathrm{~min}$ at room temperature. Crystal violet was removed by washing twice in water. Plates were allowed to airdry overnight, then crystal violet stain was eluted using $1 \%$ Triton X-100 solution on a plate shaker for $1 \mathrm{~h}$. The eluted stain was transferred to a 96-well plate and absorbance read at $595 \mathrm{~nm}$ on a Versamax plate reader (Molecular Devices Corporation, Sunnyvale, CA, USA). 


\section{Conclusions}

There is an overwhelming, unmet clinical need for targeted therapies for the treatment of UM. The cysteinyl leukotrienes are established as regulators of inflammation and have recently emerged as novel regulators of angiogenesis, two key processes in UM. For the first time, we examine the clinical relevance of $\mathrm{CysLT}_{1}$ and $\mathrm{CysLT}_{2}$ expression and in primary $\mathrm{UM}_{\mathrm{S}}$ samples and show a link between high CysLT $_{1}$ expression and primary UM patient survival. Our data highlight the involvement of both receptors with clinical features of their disease and reinforces their link to inflammatory and angiogenic pathways. We determined that antagonist drugs of $\mathrm{CysLT}_{1}$, but not $\mathrm{CysLT}_{2}$, inhibit the survival and proliferation of primary and metastatic UM cells in a specific, time- and dose-dependent manner. This effect is recapitulated in in vivo zebrafish cell line xenograft models. Antagonism of CysLT 1 in $\mathrm{UM}$ cells leads to alterations in the secretion of pro-inflammatory and pro-angiogenic secretions and a decrease in oxidative phosphorylation. The importance of the cysteinyl leukotriene receptor signalling

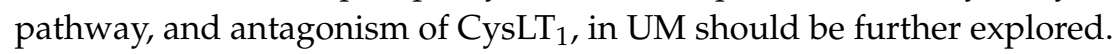

Supplementary Materials: The following are available online at http://www.mdpi.com/2072-6694/12/10/2950/s1, Figure S1: Analysis of TCGA data using MCP-Counter and ESTIMATE, Figure S2: Patient TMA control tissue. Core-core correlations of manual versus digital pathology analysis. Clinical characteristics of patients included in the TMA, Figure S3: Cell line comparison data for the clonogenic assay, Figure S4: Factors unchanged following treatment in Mel285 and OMM2.5 cells, Figure S5: Generation of OMM2.5 cell line-derived orthotopic xenograft models of UM, Table S1: Statistical analysis of TCGA UM dataset.

Author Contributions: Conceptualization, K.S., J.O. and B.N.K.; methodology, K.S., H.K., S.E.C., A.R., W.M.G., J.M.P., J.O. and B.N.K.; validation, K.S., A.B.H., R.S.-P., S.G.-M., L.D.J., H.K., S.E.C., A.R., W.M.G.; formal analysis, K.S. and B.N.K.; investigation, K.S., A.B.H., R.S.-P., S.G.-M., L.D.J., F.O., M.H., H.K., S.E.C., A.R., N.A.-A., A.V., R.B.; resources, B.N.K., S.E.C., W.M.G., A.P., A.V.; data curation, K.S.; writing-original draft preparation, K.S.; writing-review and editing, K.S., J.O., S.E.C., L.D.J., J.M.P., B.N.K.; supervision, B.N.K.; project administration, K.S. and B.N.K.; funding acquisition, K.S. and B.N.K., K.S., S.E.C., A.R., W.M.G., J.M.P., J.O. and B.N.K. interpreted the results and provided significant intellectual input. All authors have read and agreed to the published version of the manuscript.

Funding: This work was supported by an Irish Research Council Employment Based Postgraduate Scholarship (EBP/2017/473) (KS), a British Pharmacological Society Schachter Award (KS) and funding from Breakthrough Cancer Research (KS and BNK). This project area has received funding from the European Union's Horizon 2020 research and innovation programme under grant agreement no. 734907 (RISE/3D-NEONET project) (BNK). Automated image analysis work was supported by the Science Foundation Ireland Investigator Programme OPTi-PREDICT (grant code 15/IA/3104; WMG, AR) and the Science Foundation Ireland Strategic Partnership Programme Precision Oncology Ireland POI (grant code 18/SPP/3522; WMG, AR).

Acknowledgments: The authors thank Natalie Coplin for assistance with immunohistochemical staining and Husvinee Sundaramurthi for proof-reading the manuscript.

Conflicts of Interest: J.O.S. and B.N.K. are inventors on United States Patent 8916586 B2, and United States Patent 9388138 B2. The other authors declare no competing financial interests that could be construed as a potential conflict of interest.

\section{References}

1. Rao, Y.J.; Sein, J.; Badiyan, S.; Schwarz, J.K.; DeWees, T.; Grigsby, P.; Rao, P.K. Patterns of care and survival outcomes after treatment for uveal melanoma in the post-coms era (2004-2013): A surveillance, epidemiology, and end results analysis. J. Contemp. Brachytherapy 2017, 5, 453-465. [CrossRef] [PubMed]

2. Damato, B.; Heimann, H. Personalized treatment of uveal melanoma. Eye 2012, 27, 172-179. [CrossRef] [PubMed]

3. Diener-West, M.; Reynolds, S.M.; Agugliaro, D.J.; Caldwell, R.; Cumming, K.; Earle, J.D.; Hawkins, B.S.; A Hayman, J.; Jaiyesimi, I.; Jampol, L.M.; et al. Development of Metastatic Disease After Enrollment in the COMS Trials for Treatment of Choroidal Melanoma. Arch. Ophthalmol. 2005, 123, 1639-1643. [CrossRef]

4. Kuk, D.; Shoushtari, A.N.; Barker, C.A.; Panageas, K.S.; Munhoz, R.R.; Momtaz, P.; Ariyan, C.E.; Brady, M.S.; Coit, D.G.; Bogatch, K.; et al. Prognosis of Mucosal, Uveal, Acral, Nonacral Cutaneous, and Unknown Primary Melanoma from the Time of First Metastasis. Oncology 2016, 21, 848-854. [CrossRef] [PubMed]

5. Xu, L.T.; Funchain, P.F.; Bena, J.F.; Li, M.; Tarhini, A.; Berber, E.; Singh, A.D. Uveal Melanoma Metastatic to the Liver: Treatment Trends and Outcomes. Ocul. Oncol. Pathol. 2019, 5, 323-332. [CrossRef] [PubMed] 
6. Pons, F.; Plana, M.; Caminal, J.M.; Pera, J.; Fernandes, I.; Perez, J.; Garcia-Del-Muro, X.; Marcoval, J.; Penin, R.; Fabra, À.; et al. Metastatic uveal melanoma. Melanoma Res. 2011, 21, 217-222. [CrossRef]

7. Hoiom, V.; Helgadottir, H. The genetics of uveal melanoma: Current insights. Appl. Clin. Genet. 2016, 9, 147-155. [CrossRef]

8. Robertson, A.G.; Shih, J.; Yau, C.; Gibb, E.A.; Oba, J.; Mungall, K.L.; Hess, J.M.; Uzunangelov, V.; Walter, V.; Danilova, L.; et al. Integrative Analysis Identifies Four Molecular and Clinical Subsets in Uveal Melanoma. Cancer Cell 2017, 32, 204-220.e15. [CrossRef]

9. Slater, K.; Hoo, P.S.; Buckley, A.M.; Piulats, J.M.; Villanueva, A.; Portela, A.; Kennedy, B.N. Evaluation of oncogenic cysteinyl leukotriene receptor 2 as a therapeutic target for uveal melanoma. Cancer Metastasis Rev. 2018, 37, 335-345. [CrossRef]

10. Van Raamsdonk, C.D.; Griewank, K.G.; Crosby, M.B.; Garrido, M.C.; Vemula, S.; Wiesner, T.; Obenauf, A.C.; Wackernagel, W.; Green, G.; Bouvier, N.; et al. Mutations inGNA11in Uveal Melanoma. N. Engl. J. Med. 2010, 363, 2191-2199. [CrossRef]

11. Jager, M.J.; Shields, C.L.; Cebulla, C.M.; Abdel-Rahman, M.H.; Grossniklaus, H.E.; Stern, M.-H.; Carvajal, R.D.; Belfort, R.N.; Jia, R.; Shields, J.A.; et al. Uveal melanoma. Nat. Rev. Dis. Primers 2020, 6, 24. [CrossRef]

12. Moore, A.R.; Ceraudo, E.; Sher, J.J.; Guan, Y.; Shoushtari, A.N.; Chang, M.T.; Zhang, J.Q.; Walczak, E.G.; A Kazmi, M.; Taylor, B.S.; et al. Recurrent activating mutations of G-protein-coupled receptor CYSLTR2 in uveal melanoma. Nat. Genet. 2016, 48, 675-680. [CrossRef] [PubMed]

13. Luke, J.J.; Flaherty, K.T.; Ribas, A.; Long, G.V. Targeted agents and immunotherapies: Optimizing outcomes in melanoma. Nat. Rev. Clin. Oncol. 2017, 14, 463-482. [CrossRef] [PubMed]

14. Croce, M.; Ferrini, S.; Pfeffer, U.; Gangemi, R. Targeted Therapy of Uveal Melanoma: Recent Failures and New Perspectives. Cancers 2019, 11, 846. [CrossRef] [PubMed]

15. Carvajal, R.D.; Piperno-Neumann, S.; Kapiteijn, E.; Chapman, P.B.; Frank, S.; Joshua, A.M.; Piulats, J.M.; Wolter, P.; Cocquyt, V.; Chmielowski, B.; et al. Selumetinib in Combination with Dacarbazine in Patients With Metastatic Uveal Melanoma: A Phase III, Multicenter, Randomized Trial (SUMIT). J. Clin. Oncol. 2018, 36, 1232-1239. [CrossRef]

16. Singh, R.; Gupta, S.; Dastidar, S.; Ray, A. Cysteinyl Leukotrienes and Their Receptors: Molecular and Functional Characteristics. Pharmacology 2010, 85, 336-349. [CrossRef] [PubMed]

17. Lynch, K.R.; O’Neill, G.P.; Liu, Q.; Im, D.-S.; Sawyer, N.; Metters, K.M.; Coulombe, N.; Abramovitz, M.; Figueroa, D.J.; Zeng, Z.; et al. Characterization of the human cysteinyl leukotriene CysLT1 receptor. Nat. Cell Biol. 1999, 399, 789-793. [CrossRef] [PubMed]

18. Heise, C.E.; O’Dowd, B.F.; Figueroa, D.J.; Sawyer, N.; Nguyen, T.; Im, D.-S.; Stocco, R.; Bellefeuille, J.N.; Abramovitz, M.; Cheng, R.; et al. Characterization of the Human Cysteinyl Leukotriene 2 Receptor. J. Biol. Chem. 2000, 275, 30531-30536. [CrossRef]

19. Jiang, Y.; Borrelli, L.A.; Kanaoka, Y.; Bacskai, B.J.; Boyce, J.A. CysLT2 receptors interact with CysLT1 receptors and down-modulate cysteinyl leukotriene-dependent mitogenic responses of mast cells. Blood 2007, 110, 3263-3270. [CrossRef]

20. Gusach, A.; Luginina, A.; Marin, E.; Brouillette, R.L.; Besserer-Offroy, É.; Longpré, J.-M.; Ishchenko, A.; Popov, P.; Patel, N.; Fujimoto, T.; et al. Structural basis of ligand selectivity and disease mutations in cysteinyl leukotriene receptors. Nat. Commun. 2019, 10,1-9. [CrossRef]

21. Burke, L.; Butler, C.T.; Murphy, A.; Moran, B.; Gallagher, W.M.; O'Sullivan, J.; Kennedy, B.N. Evaluation of Cysteinyl Leukotriene Signaling as a Therapeutic Target for Colorectal Cancer. Front. Cell Dev. Biol. 2016, 4, 103. [CrossRef] [PubMed]

22. Duah, E.; Teegala, L.R.; Kondeti, V.; Adapala, R.K.; Keshamouni, V.G.; Kanaoka, Y.; Austen, K.F.; Thodeti, C.K.; Paruchuri, S. Cysteinyl leukotriene 2 receptor promotes endothelial permeability, tumor angiogenesis, and metastasis. Proc. Natl. Acad. Sci. USA 2018, 116, 199-204. [CrossRef] [PubMed]

23. Tsai, M.-J.; Wu, P.-H.; Sheu, C.-C.; Hsu, Y.-L.; Chang, W.-A.; Hung, J.-Y.; Yang, C.-J.; Yang, Y.-H.; Kuo, P.-L.; Huang, M.-S. Cysteinyl Leukotriene Receptor Antagonists Decrease Cancer Risk in Asthma Patients. Sci. Rep. 2016, 6, 23979. [CrossRef] [PubMed]

24. Kawahito, Y.; Sano, H.; Nakatani, T.; Yoshimura, R.; Naganuma, T.; Funao, K.; Matsuyama, M. The cysteinylLT1 receptor in human renal cell carcinoma. Mol. Med. Rep. 2011, 1, 185-189. [CrossRef] 
25. Matsuyama, M.; Funao, K.; Hayama, T.; Tanaka, T.; Kawahito, Y.; Sano, H.; Takemoto, Y.; Nakatani, T.; Yoshimura, R. Relationship Between Cysteinyl-Leukotriene-1 Receptor and Human Transitional Cell Carcinoma in Bladder. Urology 2009, 73, 916-921. [CrossRef]

26. Matsuyama, M.; Funao, K.; Kawahito, Y.; Sano, H.; Chargui, J.; Touraine, J.-L.; Nakatani, T.; Yoshimura, R. Expression of cysteinylLT1 receptor in human testicular cancer and growth reduction by its antagonist through apoptosis. Mol. Med. Rep. 2009, 2, 163-167. [CrossRef]

27. Nielsen, C.K.; Öhd, J.F.; Wikström, K.; Massoumi, R.; Paruchuri, S.; Juhas, M.; Sjölander, A. The Leukotriene Receptor CYSLT1 and 5- Lipoxygenase Are Upregulated In Colon Cancer. Adv. Exp. Med. Biol. 2003, 525, 201-204. [CrossRef]

28. Magnusson, C.; Mezhybovska, M.; Lörinc, E.; Fernebro, E.; Nilbert, M.; Sjölander, A. Low expression of CysLT1R and high expression of CysLT2R mediate good prognosis in colorectal cancer. Eur. J. Cancer 2010, 46, 826-835. [CrossRef]

29. Magnusson, C.; Liu, J.; Ehrnström, R.; Manjer, J.; Jirström, K.; Andersson, T.; Sjölander, A. Cysteinyl leukotriene receptor expression pattern affects migration of breast cancer cells and survival of breast cancer patients. Int. J. Cancer 2010, 129, 9-22. [CrossRef]

30. Möller, I.; Murali, R.; Müller, H.; Wiesner, T.; A Jackett, L.; Scholz, S.L.; Cosgarea, I.; Ap Van De Nes, J.; Sucker, A.; Hillen, U.; et al. Activating cysteinyl leukotriene receptor 2 (CYSLTR2) mutations in blue nevi. Mod. Pathol. 2016, 30, 350-356. [CrossRef]

31. Van De Nes, J.A.; Koelsche, C.; Gessi, M.; Möller, I.; Sucker, A.; Scolyer, R.A.; Buckland, M.E.; Pietsch, T.; Murali, R.; Schadendorf, D.; et al. Activating CYSLTR2 and PLCB4 Mutations in Primary Leptomeningeal Melanocytic Tumors. J. Investig. Dermatol. 2017, 137, 2033-2035. [CrossRef] [PubMed]

32. Reynolds, A.L.; Alvarez, Y.; Sasore, T.; Waghorne, N.; Butler, C.T.; Kilty, C.; Smith, A.J.; McVicar, C.; Wong, V.H.Y.; Galvin, O.; et al. Phenotype-based Discovery of 2-[(E)-2-(Quinolin-2-yl)vinyl]phenol as a Novel Regulator of Ocular Angiogenesis. J. Biol. Chem. 2016, 291, 7242-7255. [CrossRef] [PubMed]

33. Butler, C.T.; Reynolds, A.L.; Tosetto, M.; Dillon, E.T.; Guiry, P.J.; Cagney, G.; O'Sullivan, J.; Kennedy, B.N. A Quininib Analogue and Cysteinyl Leukotriene Receptor Antagonist Inhibits Vascular Endothelial Growth Factor (VEGF)-independent Angiogenesis and Exerts an Additive Antiangiogenic Response with Bevacizumab. J. Biol. Chem. 2016, 292, 3552-3567. [CrossRef] [PubMed]

34. Murphy, A.G.; Casey, R.; Maguire, A.; Tosetto, M.; Butler, C.T.; Conroy, E.; Reynolds, A.L.; Sheahan, K.; O'Donoghue, D.; Gallagher, W.M.; et al. Preclinical validation of the small molecule drug quininib as a novel therapeutic for colorectal cancer. Sci. Rep. 2016, 6, srep34523. [CrossRef]

35. Butler, C.T.; Kennedy, S.A.; Buckley, A.; Doyle, R.; Conroy, E.; Gallagher, W.M.; O'Sullivan, J.; Kennedy, B.N. 1,4-dihydroxy quininib attenuates growth of colorectal cancer cells and xenografts and regulates the TIE-2 signaling pathway in patient tumours. Oncotarget 2019, 10, 3725-3744. [CrossRef] [PubMed]

36. Castet, F.; Garcia-Mulero, S.; Sanz-Pamplona, R.; Cuellar, A.; Casanovas, O.; Caminal, J.M.; Piulats, J.M. Uveal Melanoma, Angiogenesis and Immunotherapy, Is There Any Hope? Cancers 2019, 11, 834. [CrossRef] [PubMed]

37. Foss, A.J.; A Alexander, R.; Jefferies, L.W.; Hungerford, J.L.; Harris, A.L.; Lightman, S. Microvessel count predicts survival in uveal melanoma. Cancer Res. 1996, 56, 2900-2903.

38. Mäkitie, T.; Summanen, P.; Tarkkanen, A.; Kivelä, T. Microvascular density in predicting survival of patients with choroidal and ciliary body melanoma. Investig. Ophthalmol. Vis. Sci. 1999, 40, 2471-2480.

39. Simpson, E.R.; Gallie, B.L.; Saakyan, S.; Amiryan, A.; Finger, P.T.; Chin, K.J.; Seregard, S.; Fili, M.; Wilson, M.; Haik, B.; et al. International Validation of the American Joint Committee on Cancer's 7th Edition Classification of Uveal Melanoma. JAMA Ophthalmol. 2015, 133, 376-383. [CrossRef]

40. Damato, B.; Eleuteri, A.; Taktak, A.F.; Coupland, S.E. Estimating prognosis for survival after treatment of choroidal melanoma. Prog. Retin. Eye Res. 2011, 30, 285-295. [CrossRef]

41. Jager, M.J.; Magner, J.A.B.; Ksander, B.R.; Dubovy, S.R. Uveal Melanoma Cell Lines: Where do they come from? (An American Ophthalmological Society Thesis). Trans. Am. Ophthalmol. Soc. 2016, 114, 15.

42. Duah, E.; Adapala, R.K.; Al-Azzam, N.; Kondeti, V.; Gombedza, F.; Thodeti, C.K.; Paruchuri, S. Cysteinyl leukotrienes regulate endothelial cell inflammatory and proliferative signals through CysLT2 and CysLT1 receptors. Sci. Rep. 2013, 3, 3274. [CrossRef]

43. Aharony, D. Pharmacology of Leukotriene Receptor Antagonists. Am. J. Respir. Crit. Care Med. 1998, 157, S214-S219. [CrossRef] [PubMed] 
44. Wunder, F.; Tinel, H.; Kast, R.; Geerts, A.; Becker, E.M.; Kolkhof, P.; Hütter, J.; Ergüden, J.; Härter, M. Pharmacological characterization of the first potent and selective antagonist at the cysteinyl leukotriene 2 (CysLT2) receptor. Br. J. Pharmacol. 2010, 160, 399-409. [CrossRef] [PubMed]

45. Yang, J.; Manson, D.K.; Marr, B.P.; Carvajal, R.D. Treatment of uveal melanoma: Where are we now? Ther. Adv. Med Oncol. 2018, 10, 1758834018757175. [CrossRef]

46. Heiden, M.G.V.; DeBerardinis, R.J. Understanding the Intersections between Metabolism and Cancer Biology. Cell 2017, 168, 657-669. [CrossRef]

47. Ashton, T.M.; McKenna, W.G.; Kunz-Schughart, L.A.; Higgins, G.S. Oxidative Phosphorylation as an Emerging Target in Cancer Therapy. Clin. Cancer Res. 2018, 24, 2482-2490. [CrossRef]

48. Chattopadhyay, C.; Oba, J.; Roszik, J.; Marszalek, J.R.; Chen, K.; Qi, Y.; Eterovic, K.; Robertson, A.G.; Burks, J.K.; McCannel, T.A.; et al. Elevated Endogenous SDHA Drives Pathological Metabolism in Highly Metastatic Uveal Melanoma. Investig. Opthalmology Vis. Sci. 2019, 60, 4187-4195. [CrossRef]

49. Van Der Ent, W.; Burrello, C.; Teunisse, A.F.A.S.; Ksander, B.R.; Van Der Velden, P.A.; Jager, M.J.; Jochemsen, A.G.; Snaar-Jagalska, B.E. Modeling of Human Uveal Melanoma in Zebrafish Xenograft Embryos. Investig. Opthalmology Vis. Sci. 2014, 55, 6612-6622. [CrossRef]

50. Chua, V.; Lapadula, D.; Randolph, C.; Benovic, J.L.; Wedegaertner, P.B.; E Aplin, A. Dysregulated GPCR Signaling and Therapeutic Options in Uveal Melanoma. Mol. Cancer Res. 2017, 15, 501-506. [CrossRef]

51. Garcia de Alba Graue, P.; Goyeneche, A.; Coblentz, J.; Ferrier, T.; Burnier, M.N. Expression of cysteinyl leukotriene receptors 1 and 2 in uveal melanoma. Investigative Ophthalmology \& Visual Science 2019, 60, 757.

52. Mehdawi, L.M.; Satapathy, S.R.; Gustafsson, A.; Lundholm, K.; Alvarado-Kristensson, M.; Sjölander, A. A potential anti-tumor effect of leukotriene $C 4$ through the induction of 15-hydroxyprostaglandin dehydrogenase expression in colon cancer cells. Oncotarget 2017, 8, 35033-35047. [CrossRef] [PubMed]

53. Kaliki, S.; Shields, C.L.; A Shields, J. Uveal melanoma: Estimating prognosis. Indian J. Ophthalmol. 2015, 63, 93-102. [CrossRef] [PubMed]

54. Ceraudo, E.; Horioka, M.; Mattheisen, J.M.; Hitchman, T.D.; Moore, A.R.; Kazmi, M.A.; Chi, P.; Chen, Y.; Sakmar, T.P.; Huber, T. Uveal Melanoma Oncogene CYSLTR2 Encodes a Constitutively Active GPCR Highly Biased Toward Gq Signaling. bioRxiv 2019, 663153. [CrossRef]

55. Zovko, A.; Yektaei-Karin, E.; Salamon, D.; Nilsson, A.; Wallvik, J.; Stenke, L. Montelukast, a cysteinyl leukotriene receptor antagonist, inhibits the growth of chronic myeloid leukemia cells through apoptosis. Oncol. Rep. 2018, 40, 902-908. [CrossRef] [PubMed]

56. Bellamkonda, K.; Satapathy, S.R.; Douglas, D.; Chandrashekar, N.; Selvanesan, B.C.; Liu, M.; Savari, S.; Jonsson, G.; Sjölander, A. Montelukast, a CysLT1 receptor antagonist, reduces colon cancer stemness and tumor burden in a mouse xenograft model of human colon cancer. Cancer Lett. 2018, 437, 13-24. [CrossRef]

57. Tsai, M.-J.; Chang, W.-A.; Tsai, P.-H.; Wu, C.-Y.; Ho, Y.-W.; Yen, M.-C.; Lin, Y.-S.; Kuo, P.-L.; Hsu, Y.-L. Montelukast Induces Apoptosis-Inducing Factor-Mediated Cell Death of Lung Cancer Cells. Int. J. Mol. Sci. 2017, 18, 1353. [CrossRef]

58. Desjardins, L.; Dorval, T.; Lévy, C.; Cojean, I.; Schlienger, P.; Salmon, R.J.; Validire, P.; Asselain, B. Randomised study on adjuvant therapy by DTIC in choroidal melanoma. Ophtalmologie 1998, 12, 168-173.

59. Theron, A.J.; Steel, H.C.; Tintinger, G.R.; Gravett, C.M.; Anderson, R.; Feldman, C. Cysteinyl Leukotriene Receptor-1 Antagonists as Modulators of Innate Immune Cell Function. J. Immunol. Res. 2014, 2014, 1-16. [CrossRef]

60. Papadaki, G.; Bakakos, A.; Kostikas, K.; Hillas, G.; Tsilogianni, Z.; Koulouris, N.G.; Papiris, S.; Loukides, S. Vascular endothelial growth factor and cysteinyl leukotrienes in sputum supernatant of patients with asthma. Respir. Med. 2013, 107, 1339-1345. [CrossRef]

61. Lee, K.S.; Kim, S.R.; Park, H.S.; Jin, G.Y.; Lee, Y.C. Cysteinyl leukotriene receptor antagonist regulates vascular permeability by reducing vascular endothelial growth factor expression. J. Allergy Clin. Immunol. 2004, 114, 1093-1099. [CrossRef] [PubMed]

62. Kanazawa, H.; Yoshikawa, T.; Hirata, K.; Yoshikawa, J. Effects of Pranlukast Administration on Vascular Endothelial Growth Factor Levels in Asthmatic Patients. Chest 2004, 125, 1700-1705. [CrossRef]

63. Ly, L.V.; Bronkhorst, I.H.G.; Van Beelen, E.; Vrolijk, J.; Taylor, A.W.; Versluis, M.; Luyten, G.P.M.; Jager, M.J. Inflammatory Cytokines in Eyes with Uveal Melanoma and Relation with Macrophage Infiltration. Investig. Opthalmology Vis. Sci. 2010, 51, 5445-5451. [CrossRef] [PubMed] 
64. Gammons, M.V.; Lucas, R.; Dean, R.; Coupland, S.E.; Oltean, S.; Bates, D.O. Targeting SRPK1 to control VEGF-mediated tumour angiogenesis in metastatic melanoma. Br. J. Cancer 2014, 111, 477-485. [CrossRef] [PubMed]

65. Meyer, R.D.; Mohammadi, M.; Rahimi, N. A Single Amino Acid Substitution in the Activation Loop Defines the Decoy Characteristic of VEGFR-1/FLT-1. Journal of Biological Chemistry 2006, 281, 867-875. [CrossRef] [PubMed]

66. He, Y.-G.; Mayhew, E.; Mellon, J.; Niederkorn, J.Y. Expression and Possible Function of IL-2 and IL-15 Receptors on Human Uveal Melanoma Cells. Investig. Opthalmology Vis. Sci. 2004, 45, 4240-4246. [CrossRef]

67. Csomos, I.; Nizsaloczki, E.; Nagy, G.; Mátyus, L.; Bodnár, A. Chelidonine Interferes with IL-6R/STAT3 Signaling in Uveal Melanoma Cells. Biophys. J. 2015, 108, 417a. [CrossRef]

68. Salhi, A.; Jordan, A.C.; Bochaca, I.I.; Izsak, A.; Darvishian, F.; Houvras, Y.; Giles, K.M.; Osman, I. Oxidative Phosphorylation Promotes Primary Melanoma Invasion. Am. J. Pathol. 2020, 190, 1108-1117. [CrossRef]

69. Gopal, Y.V.; Rizos, H.; Chen, G.; Deng, W.; Frederick, D.T.; Cooper, Z.A.; Scolyer, R.A.; Pupo, G.; Komurov, K.; Sehgal, V.; et al. Inhibition of mTORC1/2 Overcomes Resistance to MAPK Pathway Inhibitors Mediated by PGC1 and Oxidative Phosphorylation in Melanoma. Cancer Res. 2014, 74, 7037-7047. [CrossRef]

70. Mezhybovska, M.; Yudina, Y.; Abhyankar, A.; Sjölander, A. $\beta$-Catenin is involved in alterations in mitochondrial activity in non-transformed intestinal epithelial and colon cancer cells. Br. J. Cancer 2009, 101, 1596-1605. [CrossRef]

71. Rodríguez-Enríquez, S.; Vitalgonzalez, P.; Flores-Rodríguez, F.L.; Marín-Hernández, A.; Ruiz-Azuara, L.; Moreno-Sánchez, R. Control of cellular proliferation by modulation of oxidative phosphorylation in human and rodent fast-growing tumor cells. Toxicol. Appl. Pharmacol. 2006, 215, 208-217. [CrossRef] [PubMed]

72. Jiménez-Sánchez, A.; Cast, O.; Miller, M.L. Comprehensive Benchmarking and Integration of Tumor Microenvironment Cell Estimation Methods. Cancer Res. 2019, 79, 6238-6246. [CrossRef] [PubMed]

73. Kalirai, H.; Dodson, A.; Faqir, S.; E Damato, B.; E Coupland, S. Lack of BAP1 protein expression in uveal melanoma is associated with increased metastatic risk and has utility in routine prognostic testing. $\mathrm{Br}$. J. Cancer 2014, 111, 1373-1380. [CrossRef] [PubMed]

74. Kimmel, C.B.; Ballard, W.W.; Kimmel, S.R.; Ullmann, B.; Schilling, T.F. Stages of embryonic development of the zebrafish. Dev. Dyn. 1995, 203, 253-310. [CrossRef]

75. Rouhi, P.; Jensen, L.D.; Cao, Z.; Hosaka, K.; Länne, T.; Wahlberg, E.; Steffensen, J.F.; Cao, Y. Hypoxia-induced metastasis model in embryonic zebrafish. Nat. Protoc. 2010, 5, 1911-1918. [CrossRef] 